Nitric acid in cirrus clouds

\title{
Nitric acid partitioning in cirrus clouds: a synopsis based on field, laboratory and model studies
}

M. Krämer ${ }^{1}$, J. Beuermann ${ }^{1}$, C. Schiller ${ }^{1}$, F. Grimm ${ }^{2}$, F. Arnold ${ }^{2}$, T. Peter ${ }^{3}$, S. Meilinger ${ }^{4}$, A. Meier ${ }^{5}$, J. Hendricks ${ }^{6}$, A. Petzold ${ }^{6}$, and H. Schlager ${ }^{6}$

${ }^{1}$ FZ Jülich, Institut für Chemie der Geosphäre I: Stratosphäre, Germany

${ }^{2} \mathrm{MPI}$ für Kernphysik, Heidelberg, Atmosphärenphysik, Germany

${ }^{3}$ ETH Zürich, Institut für Atmosphärenphysik, Switzerland

${ }^{4} \mathrm{MPI}$ für Chemie Mainz, Air Chemistry Department, Germany

${ }^{5}$ Universität Köln, Inst. für Geophysik \& Meteorologie, Germany

${ }^{6}$ DLR Oberpfaffenhofen, Inst. für Physik der Atmosphäre, Germany

clouds

M. Krämer et al.

Received: 6 December 2002 - Accepted: 2 January 2003 - Published: 3 February 2003

Correspondence to: M. Krämer (m.kraemer@fz-juelich.de)

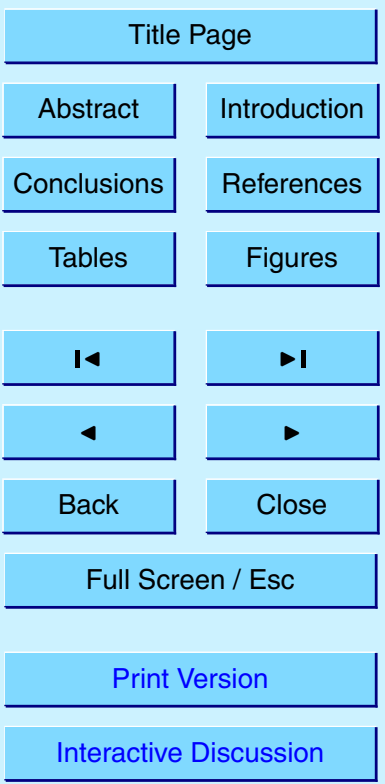

(C) EGU 2003 


\section{Abstract}

From a synopsis of field, laboratory and model studies at $T>205 \mathrm{~K}$ as well as from the field experiments POLSTAR at $T<205 \mathrm{~K}$ we derive a general picture of the partitioning of nitric acid $\left(\mathrm{HNO}_{3}\right)$ in cirrus clouds and a new hypothesis on the uptake of $\mathrm{HNO}_{3}$ on 5 ice particles:

A substantial part of nitric acid remains in the gas phase under cirrus cloud conditions. The $\mathrm{HNO}_{3}$ removed from the gas phase is distributed between interstitial aerosol and ice particles in dependence on the temperature and ice surface, respectively. In cold cirrus clouds with small ice surface areas $(T<205 \mathrm{~K})$ the partitioning is strongly in favour of interstitial ternary solution particles while in warmer cirrus clouds with large ice surface areas the uptake on ice dominates. Consequently, denitrification via sedimenting ice particles may occur only in the -more frequently occurring- warm cirrus clouds.

The $\mathrm{HNO}_{3}$ coverage on ice is found to be different for ice particles and ice films. 15 On ice films the coverage can increase with decreasing temperature from about 0.1 to 0.8 monolayer, while that on ice particles is found to decrease with temperature and $P_{\mathrm{HNO}_{3}}$ from 0.1 to 0.001 monolayer. An $\mathrm{HNO}_{3}$ uptake behaviour following dissociative Langmuir isotherms where the coverage decreases for descending temperatures may explain the observations for ice particles.

From a comparison of the $\mathrm{HNO}_{3}$ measurements with model calculations it is found that (i) the global model of Lawrence and Crutzen (1998) overestimates the $\mathrm{HNO}_{3}$ partitioning in favour of the ice particles (ii) the Langmuir surface chemistry model of Tabazadeh et al. (1999) overestimates $\mathrm{HNO}_{3}$ coverages for temperatures $\leq 210 \mathrm{~K}$. More appropriate coverages are calculated when implementing in that model a temperature dependent function for the adsorption free energy $\left(\Delta G_{\text {ads }}(T)\right)$, which is empirically derived from the coverage measurements.

\section{ACPD}

3, 413-443, 2003

\section{Nitric acid in cirrus} clouds

M. Krämer et al.

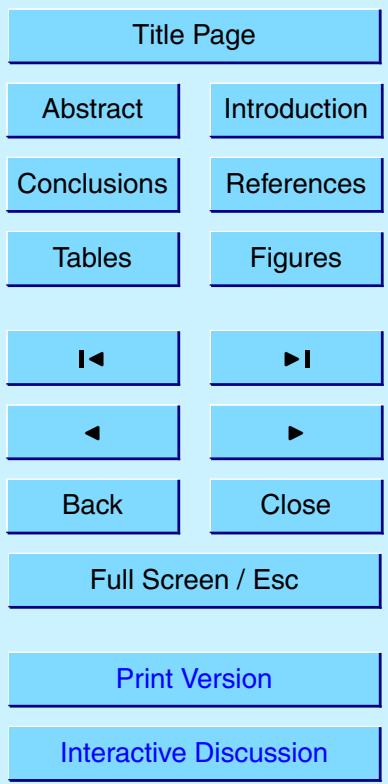

(C) EGU 2003 


\section{Introduction}

Cirrus clouds have attracted increasing attention in recent years, in particular because of their role in the radiative forcing of climate, indirect aerosol forcing as well as their relevance for the chemistry of upper tropospheric ozone. One possible mechanism important for atmospheric chemistry and trace gas distribution is the denitrification of the tropopause region by sedimenting cirrus ice particles (Lawrence and Crutzen, 1998). However, up to now the question on the partitioning of nitric acid in a cirrus cloud situation including the efficiency of nitric acid scavenging by ice particles is not satisfactorily answered.

10 Cirrus ice particles form from the fraction of the aerosol particle population suitable for ice formation at sufficiently high water vapour supersaturation. The remaining part of the aerosol population, the interstitial aerosol particles, grow to a certain size due to uptake of ambient water vapour and coexist with the ice crystals. Petzold et al. (2000) reported three particle size modes observed in cirrus clouds: accumulation, 15 haze and ice mode, whereby the haze mode represents the grown interstitial particles. In such a cirrus cloud situation, the highly water soluble nitric acid $\left(\mathrm{HNO}_{3}\right)$ present in the upper troposphere is partitioned among the gas phase $\left(\mathrm{HNO}_{3}^{\text {gas }}\right)$, the interstitial aerosol particles $\left(\mathrm{HNO}_{3}^{\text {ptcl }}\right)$, and the cirrus ice particles $\left(\mathrm{HNO}_{3}^{\text {ice }}\right)$. $\mathrm{HNO}_{3}^{\text {ptcl }}$ is taken up by the interstitial particles until thermodynamic equilibrium is reached. Parameters controlling 20 the uptake are the composition of the particle as well as temperature, pressure and the available $\mathrm{HNO}_{3}$ and $\mathrm{H}_{2} \mathrm{O}$. Simultaneously, the scavenging of $\mathrm{HNO}_{3}^{\text {ice }}$ is also controlled by temperature, pressure, the available $\mathrm{HNO}_{3}$ and the ice surface and morphology.

At present, no general picture exists describing the $\mathrm{HNO}_{3}$ partitioning in cirrus clouds, although a series of laboratory, model and field studies were performed
ACPD

$3,413-443,2003$

Nitric acid in cirrus clouds

M. Krämer et al.

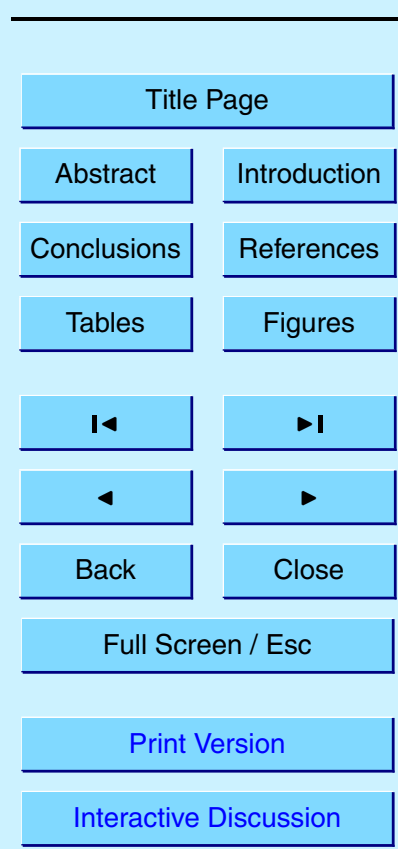

(C) EGU 2003

Laboratory studies: Diehl et al. (1995) reported from experiments for ice particles at 
$233-273 \mathrm{~K}$ and typical atmospheric (lower troposphere) gas concentrations that the uptake of $\mathrm{HNO}_{3}$ by ice crystals may be neglected against the uptake by water drops. From experiments on ice films, Zondlo et al. (1997) reported for upper tropospheric ACPD temperature $(211 \mathrm{~K})$ and pressure conditions a coverage of about 1 monolayer and a 5 partitioning between gas phase and ice particles of $0-100 \% \mathrm{HNO}_{3}^{\text {ice }}$ depending on the surface area of ice. Experiments of Abbatt (1997) on thin ice films show coverages of $0.1-0.3$ monolayer in the temperature range $248 \mathrm{~K}-208 \mathrm{~K}$ for $\mathrm{HNO}_{3}$ vapour pressures $\left(P_{\mathrm{HNO}_{3}}\right)$ much greater than those prevailing in the upper troposphere. These findings are confirmed by the recent study of Hynes et al. (2002) but are different to the 10 findings of Hudson et al. (2002), who reported for comparable conditions lower $\mathrm{HNO}_{3}$ coverages and a much stronger temperature dependence of the $\mathrm{HNO}_{3}$ uptake on ice films. Arora et al. (1999) performed experiments for ice particles at $230 \mathrm{~K}, P_{\mathrm{HNO}_{3}}$ much greater than in the upper troposphere and different ice surface areas. They report a coverage of about 0.1 monolayer and a partitioning of $35-100 \% \mathrm{HNO}_{3}^{\text {ice }}$ dependent on 15 the ice surface area.

Model studies: Assuming dissociative Langmuir uptake of nitric acid on ice, Tabazadeh et al. (1999) derived for upper tropospheric $\mathrm{HNO}_{3}$ vapour pressure a partitioning in the range of $0.03-100 \% \mathrm{HNO}_{3}^{\text {ice }}$ depending on the ice number density 20 and inversely on the temperature $(210-240 \mathrm{~K})$. Using the model of Tabazadeh et al. (1999), Meier and Hendricks (2002) show a partitioning range between $0-100 \%$ $\mathrm{HNO}_{3}^{\text {ice }}$ at $\mathrm{T}=225 \mathrm{~K}$ mainly depending on the efficiency of $\mathrm{HNO}_{3}$ adsorption which was varied in that study to perform a sensitivity analysis of upper tropospheric chemistry on $\mathrm{HNO}_{3}$ uptake on ice. Model calculations of Meilinger et al. (1999), based on field data at $\mathrm{T}=196 \mathrm{~K}$ (POLSTAR 1997, see below) result in $1 \% \mathrm{HNO}_{3}^{\text {ice }}$ assuming that the ice surface is covered by a thin ternary liquid layer.

Field experiments: based on measurements in wave clouds during the field experiment SUCCESS in 1996, Weinheimer et al. (1998) supposed that almost all gas

\section{Nitric acid in cirrus clouds}

M. Krämer et al.

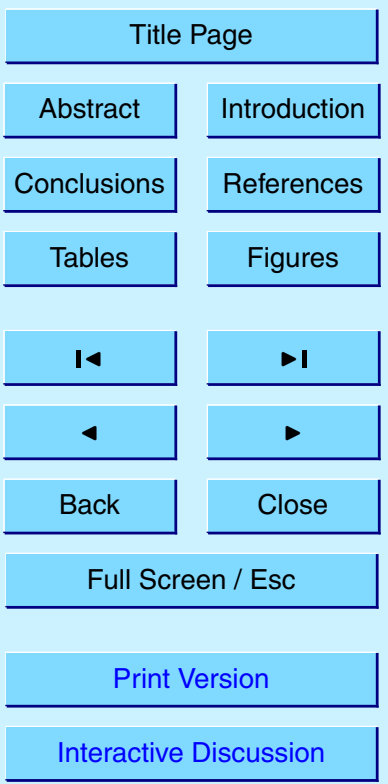

(C) EGU 2003 
phase $\mathrm{HNO}_{3}$ is deposited rapidly on the ice particles. This conclusion was drawn from the measurement of particle $\mathrm{NO}_{\mathrm{y}}$ and an assumption on the ambient $\mathrm{HNO}_{3} / \mathrm{NO}_{\mathrm{y}}$ ratio. However, no gas phase $\mathrm{HNO}_{3}$ was measured during this campaign. Recently, Hudson et al. (2002) provide the missing parameter wherewith it can be estimated that 5 about half of the $\mathrm{HNO}_{3}$ is taken up by the ice particles, yielding a coverage of about 0.01 monolayer. Two airborne Polar Stratospheric Aerosol Experiments (POLSTAR) were performed in 1997 and 1998 in the Northern part of Europe. Cold cirrus clouds $(T<205 \mathrm{~K})$ were encountered several times and for the first time all parameters necessary to determine the partitioning of nitric acid in cirrus clouds are recorded 10 simultaneously during these experiments. From POLSTAR 1997 Meilinger et al. (1999) found indication that the major part of $\mathrm{HNO}_{3}$ remains in interstitial ternary solution particles and not on the ice $\left(\mathrm{HNO}_{3}^{\text {ice }}<0.01\right.$ monolayer). However, for POLSTAR 1997 the amounts of both $\mathrm{HNO}_{3}^{\text {gas }}$ and $\mathrm{HNO}_{3}^{\text {ice }}$ were close to the detection limits of the respective instruments. More comprehensive measurements were obtained during the 15 POLSTAR 1998 experiment.

Here, we present a method to determine $\mathrm{HNO}_{3}$ partitioning for cold temperatures ( $T<205 \mathrm{~K}$ ) from the data of the POLSTAR experiments. Using this method, we reanalyse the data from POLSTAR 1997 and evaluate those from POLSTAR 1998. In addi20 tion, we combine these results with a part of the above mentioned field and laboratory measurements and model calculations performed for temperatures warmer than $205 \mathrm{~K}$. From this synopsis of data, we obtain a preliminary general view of the partitioning of $\mathrm{HNO}_{3}$ in cirrus clouds including new information on the uptake of nitric acid on ice particles and on the associated free adsorption enthalpies and energies. Furthermore, 25 we consider the parameterization of $\mathrm{HNO}_{3}$ partitioning used by Lawrence and Crutzen (1998) with respect to the measurements and we compare the measured $\mathrm{HNO}_{3}$ coverages with coverages calculated for the field conditions with the commonly used surface chemistry model of Tabazadeh et al. (1999).
ACPD

3, 413-443, 2003

\section{Nitric acid in cirrus clouds}

M. Krämer et al.

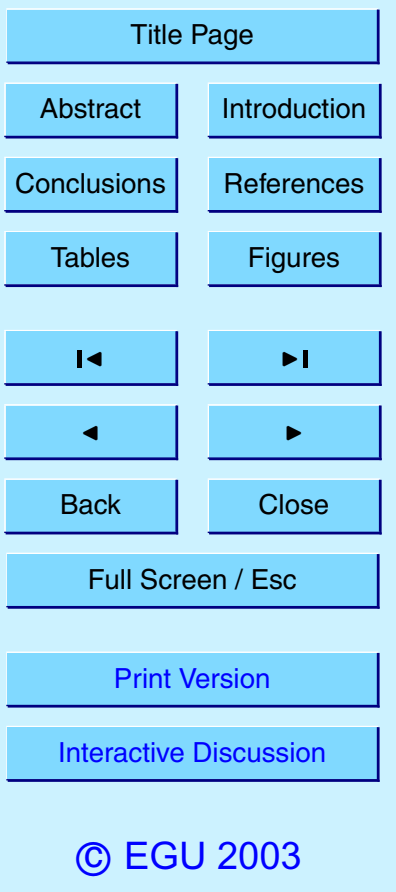




\section{Methods}

2.1. POLSTAR field experiments: Instrumentation

During the POLSTAR field campaigns, the instruments listed in Table 5 were on board of the "Deutsches Zentrum für Luft- und Raumfahrt" (DLR) research aircraft Falcon. $5 \mathrm{HNO}_{3}^{\text {ice }}, \mathrm{HNO}_{3}^{\text {gas }}$, particle size spectra (in 1997 measured with different instruments, see Meilinger et al., 1999), total water as well as meteorological parameters were measured simultaneously at $1 \mathrm{~Hz}$ sampling rate during each flight.

\subsubsection{Measurement of nitric acid on ice particles}

A forward-backward $\mathrm{NO}_{\mathrm{y}}$ detector (Feigl et al., 1999; Ziereis et al., 2000) is used to 10 measure $\mathrm{HNO}_{3}^{\text {ice }}$. The difference between two $\mathrm{NO}_{y}$ signals measured with the forward and the backward pointing inlet of the detector is interpreted as the $\mathrm{NO}_{\mathrm{y}}$ on particles, which corresponds approximately to $\mathrm{HNO}_{3}$. Because the forward inlet samples particles strongly subisokinetically, the $\mathrm{NO}_{y}$ signal is enhanced by a factor of 140 for particles larger than about $4 \mu \mathrm{m}$ in radius. Smaller particles are sampled with much 15 lesser efficiency, the mean enhancement factor of the interstitial particles is only $\approx 5$. These sampling characteristics of the inlet were recently evaluated with the computational fluid dynamics model CFX. Nevertheless, a part of the $\mathrm{NO}_{\mathrm{y}}$ signal maybe caused by these particles. Thus the measurements are interpreted as maximum $\mathrm{HNO}_{3}$ on ice particles $\left(\mathrm{HNO}_{3}^{\text {ice }}\right)_{\text {max }}$, which for simplicity is referred to as $\mathrm{HNO}_{3}^{\text {ice }}$ in the following.

20 The recent enhancement factors differ from those used by Meilinger et al. (1999): 90 for ice and 20 for the interstitial aerosol particles. On this basis Meilinger et al. (1999) found that the measured $\mathrm{NO}_{\mathrm{y}}$-signal must be attributed to interstitial ternary solution particles. Since this result is strongly dependent on the sampling characteristics of the forward-backward inlet superposed by the size spectrum of interstitial and ice particles,
ACPD

$3,413-443,2003$

Nitric acid in cirrus clouds

M. Krämer et al.

Title Page

Abstract

Introduction

Conclusions

Tables

References

Figures

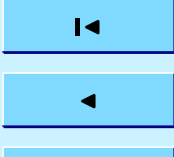

$\rightarrow$

Back

Close

Full Screen / Esc

Print Version

Interactive Discussion

(C) EGU 2003 


\subsubsection{Measurement of gas phase nitric acid}

$\mathrm{HNO}_{3}^{\text {gas }}$ was measured using the Ion Molecule Reaction Mass Spectrometer (IMRMS, Schneider, 1998). The uncertainty of the measurement is $80 \% . \mathrm{HNO}_{3}^{\text {gas }}$ was sampled with a forward pointing inlet having an enhancement factor of 4.5 for ice parti5 cles. Therefore, $\mathrm{HNO}_{3}$ from evaporating particles might contaminate the $\mathrm{HNO}_{3}^{\text {gas }}$ signal. Then, an increase of the signal should be seen when a cirrus cloud is penetrated, where not only ice particles but also the interstitial particles are sampled with their respective enhancement factors. This is not the case, as can be seen from Fig. 1 (upper panel), where $\mathrm{HNO}_{3}^{\text {gas }}$ is shown as green curve and the signal of $\mathrm{HNO}_{3}^{\text {ice }}$ enhanced by a 10 factor of 140- in red. This finding is consequent, because even with the enhancement factor of 4.5 of the $\mathrm{HNO}_{3}^{\text {gas }}$ inlet the signal from particles show values much lower than the signal from the gas phase. Therefore, we conclude that the error in the $\mathrm{HNO}_{3}^{\text {gas }}$ measurement caused by evaporating particles is small compared to the large uncertainty mentioned above.

\subsubsection{Measurement of total water}

The total amount of $\mathrm{H}_{2} \mathrm{O}$ was sampled with a subisokinetic forward pointing inlet. The enhancement factor for ice particles is about 8. The detection of $\mathrm{H}_{2} \mathrm{O}$ was performed using the Fast In situ Stratospheric Hygrometer (FISH, Schiller et al., 1999). The accuracy of the measurement is about $5 \%$.

\subsubsection{Measurement of particle size spectra $\left(\Rightarrow\right.$ Vol $^{\text {ptcl }}$, Surf $\left.{ }^{\mathrm{ice}}\right)$}

The instruments used to measure the particle number size spectrum from $7 \mathrm{~nm}$ up to $20 \mu \mathrm{m}$ in radius (UCPC, CPC, FSSP) are listed in Table 5 and are described in detail by Petzold et al. (2000). The superposition of three lognormal distributions is found to fit best the measured particle size spectra. Because of the low number concentration
ACPD

$3,413-443,2003$

\section{Nitric acid in cirrus} clouds

M. Krämer et al.

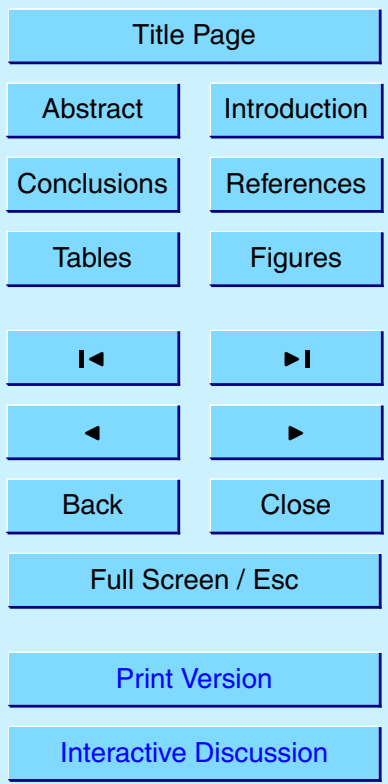

(C) EGU 2003 
have to be used as basis for the fitting procedure to obtain a sufficient counting statistics for the FSSP. This requirement reduces the time resolution of the data analysis to the two cirrus events I and II. For each of the two events the fitted mean particle size spectrum is shown in Fig. 1 (left and right lower panel), the parameters of the fits are 5 listed in Table 5. In the figure the three particle modes are shown for both cirrus events. Petzold et al. (2000) refers the smallest particles as accumulation mode, the middle as haze mode and the large as ice mode. Here, we summarize the accumulation and haze mode to the interstitial aerosol particles. For the further data analysis, the volume of the interstitial particles ( $\mathrm{Vol}^{\text {ptcl }}$ ) and the surface of the cirrus ice particles (Surf ${ }^{\text {ice }}$ ) is 10 determined by integrating the respective modes of the fitted distributions. As shown by Schlager (2002), the integrated ice surfaces are underestimated when comparing with the ice water amount measured with the FISH instrument. Therefore, Schlager (2002) corrected the ice surface on the basis of the $\mathrm{H}_{2} \mathrm{O}$ measurements (we note here that the ice surface for POLSTAR 1997 is also estimated on the basis of the FSSP/FISH measurements because of the large uncertainty in the surface determination from the MASP measurement). We rate the uncertainties of Vol ${ }^{\text {ptcl }}$ and Surf ${ }^{\text {jee }}$ to a factor of \pm 2 .

\section{2. $\mathrm{HNO}_{3}$ partitioning: model calculations based on field data}

The amounts of $\mathrm{HNO}_{3}^{\text {gas }}, \mathrm{HNO}_{3}^{\text {ice }}$ and $\mathrm{HNO}_{3}^{\text {ptcl }}$ have to be known in order to determine the partitioning of $\mathrm{HNO}_{3}$ in cirrus clouds. During POLSTAR 1997 and $1998, \mathrm{HNO}_{3}^{\text {gas }}$ and $\mathrm{HNO}_{3}^{\text {ice }}$ and additionally the volume of the interstitial particles Vol ${ }^{\text {ptcl }}$ were measured, but $\mathrm{HNO}_{3}^{\text {ptcl }}$ was missing. Here, we describe how this missing parameter can be deduced from the measurements by use of a model.

For the model calculations we used an analytic expression for the composition of aqueous $\mathrm{HNO}_{3}-\mathrm{H}_{2} \mathrm{SO}_{4}-\mathrm{H}_{2} \mathrm{O}$ aerosols including gas phase removal of $\mathrm{HNO}_{3}$, based on measurements of equilibrium vapour pressures (Carslaw et al., 1995). The parameterization is valid over the range of water partial pressure $\mathrm{p}_{w}, 2 \cdot 10^{-5} \mathrm{mb}<\mathrm{p}_{w}<2 \cdot 10^{-3}$ $\mathrm{mb}$, and temperature $\mathrm{T}, 185 \mathrm{~K}<\mathrm{T}<240 \mathrm{~K}$ (Carslaw et al., 1995). Using this expression

ACPD

$3,413-443,2003$

\section{Nitric acid in cirrus} clouds

M. Krämer et al.

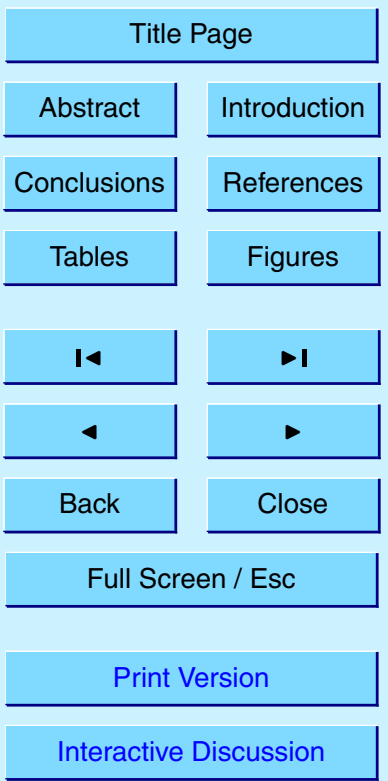

(C) EGU 2003 
we assume that the interstitial particles are ternary solution droplets $\left(\mathrm{HNO}_{3}-\mathrm{H}_{2} \mathrm{SO}_{4}\right.$ $-\mathrm{H}_{2} \mathrm{O}$ ), which probably are a major component of the aerosol particles in the upper troposphere.

The procedure to determine $\mathrm{HNO}_{3}^{\text {ptcl }}$ - similar as in Meilinger et al. (1999) - is as 5 follows: The input parameters for the model are $\mathrm{T}, \mathrm{p}, \mathrm{H}_{2} \mathrm{O}$ (measured) and the initial total amounts of $\mathrm{H}_{2} \mathrm{SO}_{4}^{\text {total }}$ and $\mathrm{HNO}_{3}^{\text {total }}$ (unknown). Model output parameters are Vol ${ }^{\text {ptcl }}, \mathrm{HNO}_{3}^{\text {gas }}$ (measured) and $\mathrm{HNO}_{3}^{\text {ptcl }}$ (wanted). The unknown model input parameters $\mathrm{H}_{2} \mathrm{SO}_{4}^{\text {total }}$ and $\mathrm{HNO}_{3}^{\text {total }}$ are now varied until the model output values $\mathrm{Vol}^{\text {ptcl }}$ and $\mathrm{HNO}_{3}^{\text {gas }}$ match the measured values. The respective $\mathrm{HNO}_{3}^{\text {ptcl }}$ is the desired value.

10 The condition of the existence of a cirrus cloud is met by setting $\mathrm{H}_{2} \mathrm{O}=\mathrm{H}_{2} \mathrm{O}_{\text {sat }}^{\text {ice }}(=$ water saturation with respect to ice) in the model calculations, that means assuming coexistence of ternary solution and ice particles in cirrus clouds. A unique value for $\mathrm{HNO}_{3}^{\text {ptcl }}\left(\mathrm{H}_{2} \mathrm{SO}_{4}^{\text {total }}, \mathrm{HNO}_{3}^{\text {total }}\right)$ is found for each of the events registered during the POLSTAR experiments.

15 The composition of the particle population in the upper troposphere is not well known. Possibly, a substantial part of the particles contain the highly water soluble atmospheric trace substance ammonia $\left(\mathrm{NH}_{3}\right)$, which would strongly influence the uptake of $\mathrm{HNO}_{3}^{\text {ptcl }}$ (Kärcher and Solomon, 1999). To obtain an estimation of the magnitude of $\mathrm{HNO}_{3}^{\text {ptcl }}$ in the presence of ammonia in the interstitial particles, we additionally calcu20 late $\mathrm{HNO}_{3}^{\text {ptcl }}$ in the way described here, but assuming that the interstitial particles consist of $\mathrm{HNO}_{3}-\mathrm{H}_{2} \mathrm{SO}_{4}-\mathrm{H}_{2} \mathrm{O}+\mathrm{NH}_{3}$. Here, we used the model AIM II (Aerosol Inorganics Model, Clegg et al. (1998), available at http://www.hpc1.uea.ac.uk/ e770/aim.html). Since an additional new parameter is introduced in the model calculations, a unique solution $\mathrm{HNO}_{3}^{\text {ptcl }}\left(\mathrm{H}_{2} \mathrm{SO}_{4}^{\text {total }}, \mathrm{HNO}_{3}^{\text {total }}\right)$ is now found for a given $\mathrm{NH}_{3}^{\text {total }}$. We choose a 25 case with a very high value for $\mathrm{NH}_{3}^{\text {total }}(0.7 \mathrm{ppb})$ to estimate the maximum $\mathrm{HNO}_{3}^{\text {ptcl }}$ in the presence of ammonia.

ACPD

3, 413-443, 2003

Nitric acid in cirrus clouds

M. Krämer et al.

Title Page

Abstract Introduction

Conclusions

Tables References Figures

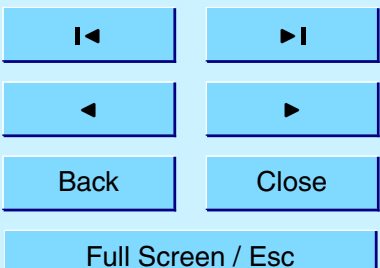

Full Screen / Esc

Print Version

Interactive Discussion

(C) EGU 2003 


\section{Nitric acid partitioning in cirrus clouds}

ACPD

In this section we will discuss the new results for $\mathrm{HNO}_{3}$ partitioning in the cold cirrus observed during the POLSTAR experiments. We then combine the results for low temperatures with those for warmer cirrus taken from the literature to achieve a first

5 impression of a general picture of $\mathrm{HNO}_{3}$ partitioning. Finally, the parameterization for $\mathrm{HNO}_{3}$ partitioning in cirrus used by Lawrence and Crutzen (1998) to estimate the denitrification of the upper troposphere, and the partitioning modeled by Tabazadeh et al. (1999) are compared with the measurements.

\subsection{Nitric acid partitioning in POLSTAR cold cirrus clouds}

10 During POLSTAR 1998, three cirrus events were encountered at the flight from Kiruna to Stockholm on 26 January 1998, all caused by cold, thin cirrus clouds with a low water content and small ice crystals, which are typical for northern regions in wintertime. The same type of clouds was detected during POLSTAR 1997 (see Meilinger et al., 1999). Nitric acid and particle size spectra measured in 1998 are shown in Fig. 1. The first two 15 peaks in $\mathrm{HNO}_{3}^{\text {ice }}$, registered shortly before the end of the flight (red line in the upper panel of Fig. 1; note that the enhanced signal is shown), are averaged for this study and denoted as event I. The next cirrus is recorded already at the descent near Stockholm and is here referred to as event II.

The $\mathrm{HNO}_{3}$ partitioning in the cold cirrus is determined as described in Sect. 2.2 and 20 is shown in Table 3 (columns framed with dual bars). The upper three rows show the relative partitioning of $\mathrm{HNO}_{3}$ between the gas phase, the interstitial and the ice particles. The lower rows show the basic measured parameters (in black) and resultant calculated values (in grey).

In all three cirrus events detected during POLSTAR 1997 and 1998, the main fraction of the initial $\mathrm{HNO}_{3}$ remained in the gas phase. A substantial amount of $\mathrm{HNO}_{3}$ was found in the interstitial particles (assumed to be ternary solutions) and only very little $\mathrm{HNO}_{3}$ was taken up by the ice particles, as already indicated by the analysis of the POLSTAR

\section{Nitric acid in cirrus clouds}

M. Krämer et al.

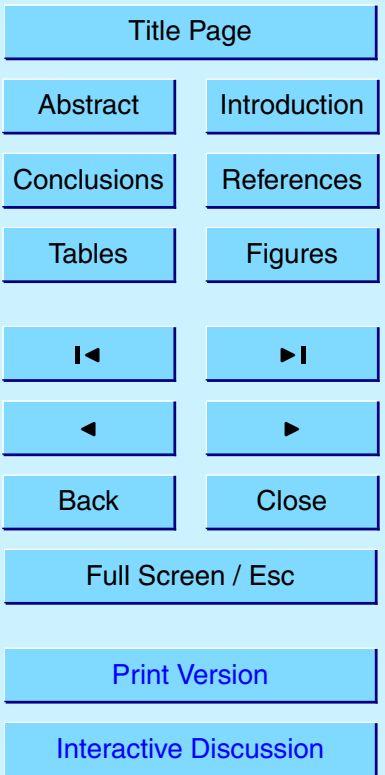

(C) EGU 2003 
1997 experiment performed by Meilinger et al. (1999). Assuming that the interstitial particles contain a large amount of additional ammonia, one expects a larger uptake of $\mathrm{HNO}_{3}$. The values in angular brackets in Table 3, event II, represent this case. The $\mathrm{HNO}_{3}$ in the gas phase decreases from about two third to about one third of the total $5 \mathrm{HNO}_{3}$, but even then the gas phase was not completely depleted.

Therefore, we conclude that there is no competition in the uptake of $\mathrm{HNO}_{3}$ between interstitial and ice particles. Equilibrium with the gas phase is reached for both (see also Sect. 4.2.1), although only a part of the $\mathrm{HNO}_{3}$ is removed from the gas phase. The processes of $\mathrm{HNO}_{3}$ scavenging of interstitial and ice particles can therefore be 10 regarded as independent from each other under cirrus cloud conditions. The stability of this result is demonstrated by considering the uncertainty range of the $\mathrm{HNO}_{3}$ uptake on ice particles: the large measurement errors of $80 \%$ and a factor of 2 of the parameters $\mathrm{HNO}_{3}^{\text {gas }}$ and $\mathrm{Vol}$ ptcl do not propagate to the range of $\mathrm{HNO}_{3}^{\text {ice }}$ (values in parantheses in Table 3 ) to such an extent that the result for the partitioning would loose its clearness.

\subsection{Nitric acid partitioning in warm cirrus clouds}

For a general picture of nitric acid partitioning in cirrus clouds, we add to the findings for cold cirrus some results for warmer cirrus taken from the literature: the field experiment SUCCESS (Weinheimer et al., 1998), a recent model study (Meier and Hendricks, 2002) and a laboratory experiment (Arora et al. (1999): this work is suitable for comparison with field measurements because the experiments were performed for a population of ice particles and not on ice films. The results of these studies for $\mathrm{HNO}_{3}$ partitioning are also shown in the upper three rows of Table 3 (the experiments are also shortly described in Sect. 4.1).

Most notable is, that in the studies for warmer temperatures ( $T \geq 209 \mathrm{~K})$ a much larger uptake of $\mathrm{HNO}_{3}$ on the ice particles is found and that the uptake increases with temperature, the amount of $\mathrm{H}_{2} \mathrm{O}$ and the ice surface area. (see Table 3, basic measured and calculated parameters). On the other hand no uptake of $\mathrm{HNO}_{3}$ in interstitial particles is stated for these studies. This reflects the known uptake behaviour of ternary solution

ACPD

$3,413-443,2003$

\section{Nitric acid in cirrus} clouds

M. Krämer et al.

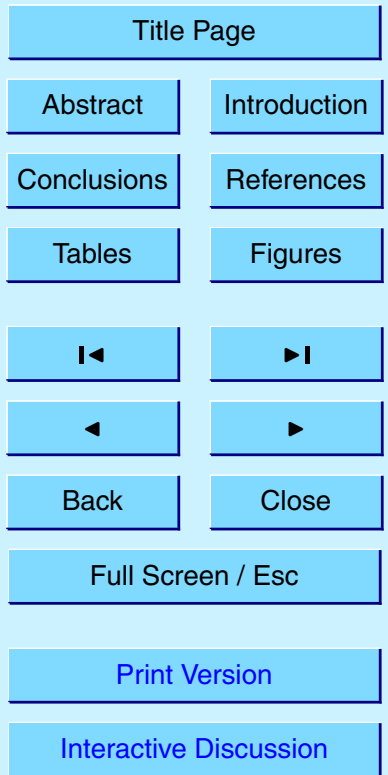

(C) EGU 2003 
particles, which is strongly dependent on the temperature in such a way that no uptake of $\mathrm{HNO}_{3}$ occurs at $\mathrm{T}>205 \mathrm{~K}$ (Carslaw et al., 1995).

However, the question on $\mathrm{HNO}_{3}$ partitioning in warm cirrus in the presence of interstitial particles containing ammonia is still open. In this case, competition between 5 interstitial and ice particles could occur, which may lead to a partitioning in favour of the interstitial instead of the ice particles.

\subsection{General view of nitric acid partitioning}

A schematic diagram of the partitioning of nitric acid in cirrus clouds between interstitial aerosol and ice particles is shown in Fig. 2. The red line shows the above discussed $\mathrm{HNO}_{3}$ uptake on interstitial particles in dependence on the temperature, the green line that on ice particles, the blue line shows the amount of available $\mathrm{H}_{2} \mathrm{O}$ and the turquoise line the ice surface area of the cirrus cloud. $\mathrm{H}_{2} \mathrm{O}$ controls the temperature of cirrus formation ( $\left.\mathrm{T}_{\text {cirrus }}\right)$, whereby the smaller the amount of water the lower is the temperature at which the ice supersaturation required for cirrus formation is reached and the smaller is the ice surface area of the cirrus cloud.

In summary we find that both $\mathrm{HNO}_{3}^{\text {ice }}$ and $\mathrm{HNO}_{3}^{\text {ptcl }}$ are controlled by the temperature of the cirrus via the amount of available water $\left(\mathrm{HNO}_{3}^{\text {ptcl, ice }} \propto \mathrm{T}_{\text {cirrus }} \propto \mathrm{H}_{2} \mathrm{O} \propto\right.$ ice surface area), whereby in cold cirrus clouds $(T<205 \mathrm{~K})$ with low water content and a small ice surface area the partitioning is in favour of the interstitial particles and in warmer cirrus clouds ( $T>205 \mathrm{~K})$ with a higher water content and a large ice surface area the uptake on ice preponderates.

\subsection{Denitrification of the upper troposphere via cirrus clouds}

Denitrification of the upper troposphere is estimated by Lawrence and Crutzen (1998) using the global offline tracer model MATCH. This estimation is based on the relative 25 uptake of nitric acid in dependence on the surface of cirrus clouds. In Fig. 3 (dashed dotted line) the parameterization of lowest relative $\mathrm{HNO}_{3}$ uptake used by Lawrence and

ACPD

$3,413-443,2003$

Nitric acid in cirrus clouds

M. Krämer et al.

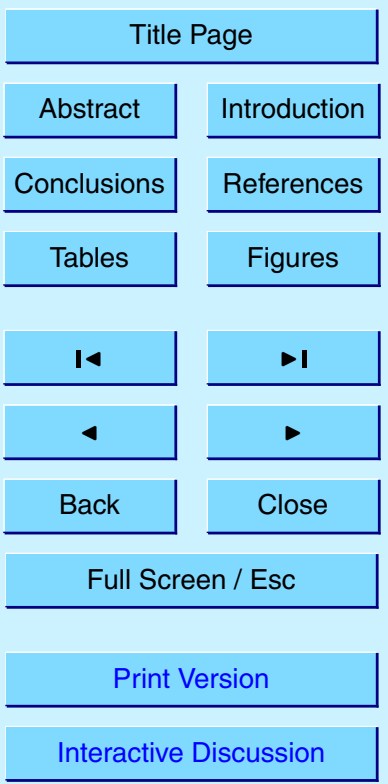

(C) EGU 2003 
Crutzen (1998) $\left(10^{14} \mathrm{molec} / \mathrm{cm}^{2}\right.$ independent on temperature) is plotted versus the ice ACPD surface area in comparison with those found for POLSTAR $1997+1998$ (red, green and Burgundy diamonds), SUCCESS 1996 (olive diamonds) and by Arora et al. (1999) (blue crosses). Very clearly it can be seen that in the model of Lawrence and Crutzen 5 (1998) the uptake of nitric acid by cirrus ice is overestimated by a factor of about $2-10$ for the ice surfaces detected during the field experiments, which may lead to an overestimation of the denitrification of the upper troposphere by sedimenting cirrus cloud particles. Tabazadeh et al. (1999) already stated an overestimation when comparing the partitioning of Lawrence and Crutzen (1998) with those modeled using a Langmuir surface chemistry model (see Fig. 3, open rectangles; blue: $230 \mathrm{~K}$, olive: $210 \mathrm{~K}$; model see Sect. 4.1). However, when comparing the partitioning found by Tabazadeh et al. (1999) with the field data points $\left(P_{\mathrm{HNO}_{3}}\right.$ is similar, but temperatures are different), it becomes obvious that the modeled values also exceeds the measured, escpecially for colder temperatures.

\section{Nitric acid uptake on ice}

A synopsis of experimentally determined uptake of $\mathrm{HNO}_{3}$ on ice will be shown here in terms of ice surface coverage $\left(\mathrm{HNO}_{3}^{\text {cov }}=\mathrm{HNO}_{3}^{\text {ice }} /\right.$ Surf ${ }^{\text {ice }} ; \mathrm{HNO}_{3}^{\text {cov }} \cdot 10^{-15} \mathrm{~cm}^{2} \mathrm{molec}^{-1}$ $\equiv 1$ monolayer $\equiv \theta$ ), whereby those studies showing quantitative data in comparable units are reported. The dependence of the uptake of $\mathrm{HNO}_{3}$ on ice on the temperature and the initial $P_{\mathrm{HNO}_{3}}$ will also be discussed. Furthermore, coverages calculated with a Langmuir surface chemistry model for the conditions of the field and laboratory studies are compared with the measurements and the dependence of the adsorption free energies and enthalpies on temperature will be presented.

Nitric acid in cirrus clouds

M. Krämer et al.

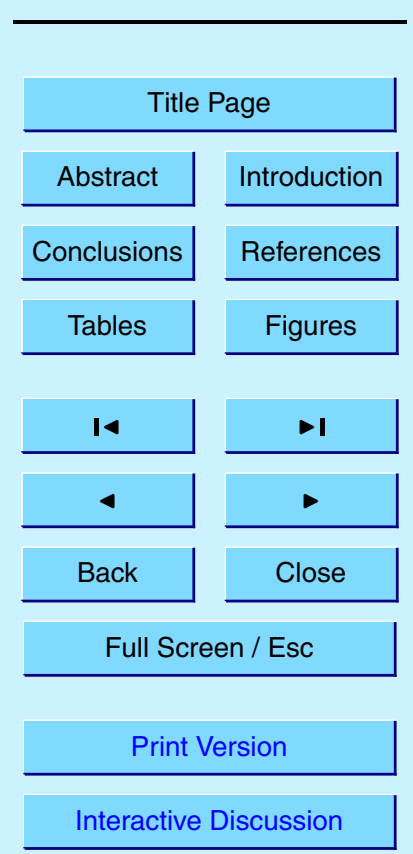

(C) EGU 2003 

versus temperature in the upper right panel for the field experiments SUCCESS 1996 (Weinheimer et al., 1998), POLSTAR 1997 (Meilinger et al., 1999), POLSTAR 1998 and 5 the laboratory studies of Arora et al. (1999), Abbatt (1997), Hynes et al. (2002) and Hudson et al. (2002). Furthermore, the model of Tabazadeh et al. (1999) is applied to a part of the experimental data and the modeled coverages are then compared to the measured. Finally, the lower right panel of Fig. 4 shows the free adsorption energies $\Delta G_{\text {ads }}$ and enthalpies $\Delta H_{\text {ads }}$ derived from the measured data. In the following a short description of the data shown here is given.

Field study SUCCESS 1996, Weinheimer et al. (1998) (209K): The $\mathrm{HNO}_{3}$ coverage found during the field experiment SUCCESS 1996 (olive diamond in Fig. 4) is measured using a similar technique (forward-backward $\mathrm{NO}_{\mathrm{y}}$ detector) than during 15 POLSTAR. The respective temperature and $P_{\mathrm{HNO}_{3}}$ are taken from Hudson et al. (2002).

Field studies POLSTAR 1997 + 1998 (196K - 202K): The POLSTAR measurements in cold cirrus clouds are plotted as red, green and Burgundy diamonds in Fig. 4. The downward pointing arrows represent error bars, indicating that $\mathrm{HNO}_{3}^{\text {ice }}$ measurements 20 are upper limits (see Sect. 2.1). A strong decrease of $\mathrm{HNO}_{3}^{\text {cov }}$ of ice particles with temperature can be seen in the upper right panel.

Laboratory study of Arora et al. (1999) (233K): This laboratory study (blue crosses in Fig. 4) is performed for ice particles with different integral ice surfaces at a $\mathrm{P}_{\mathrm{HNO}_{3}}$ 25 of $5 \cdot 10^{-6} \mathrm{hPa}$ (> upper tropospheric $P_{\mathrm{HNO}_{3}}$ ). $\mathrm{HNO}_{3}^{\text {cov }}$ is found to be nearly constant for the different ice surface areas, while the percentage uptake on ice increases with increasing surface area (see also Fig. 3).

\section{Nitric acid in cirrus clouds}

M. Krämer et al.

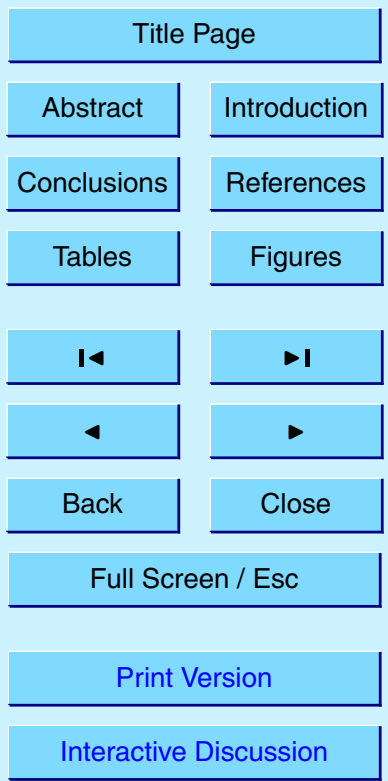

(C) EGU 2003 
Laboratory study of Abbatt (1997) (208K - 248K): In this laboratory study (turquoise plus in Fig. 4), the uptake on $\mathrm{HNO}_{3}$ on thin ice films is found to increase slightly with decreasing temperature (for $P_{\mathrm{HNO}_{3}}$ of $8-12 \cdot 10^{-7} \mathrm{hPa}>$ upper tropospheric $P_{\mathrm{HNO}_{3}}$ ). At 228K measurements for different initial amounts of gas phase $\mathrm{HNO}_{3}$ are shown, 5 whereby the uptake slightly decreases with decreasing gas phase $\mathrm{HNO}_{3}$ (upper left panel).

Laboratory study of Hynes et al. (2002) (210K - 248K): This recent laboratory study on uptake of $\mathrm{HNO}_{3}$ on thin ice films (middle-blue plus in Fig. 4) confirms the results of 10 Abbatt (1997). The $P_{\mathrm{HNO}_{3}}$ was $11.3 \cdot 10^{-7} \mathrm{hPa}$ for all temperatures and the experiments for varying $P_{\mathrm{HNO}_{3}}$ were at $218 \mathrm{~K}$.

Hynes et al. (2002) assume that the $\mathrm{HNO}_{3}$ uptake on ice is Langmuir like and dissociative, that means that the uptake is dependent on the $P_{\mathrm{HNO}_{3}}$ at constant temperatures and that after the adsorption process $\mathrm{HNO}_{3}$ dissociates on the surface to $\mathrm{H}^{+}$and $\mathrm{NO}_{3}^{-}$. 15 The dissociative Langmuir adsorption isotherm is described by

$\Theta=\frac{\sqrt{\mathrm{K}_{\mathrm{eq}} \cdot \mathrm{P}_{\mathrm{HNO}_{3}}}}{\left(1+\sqrt{\mathrm{K}_{\mathrm{eq}} \cdot \mathrm{P}_{\mathrm{HNO}_{3}}}\right)}$

with $\theta$ : equilibrium surface coverage ( $\equiv$ monolayer), $\mathrm{K}_{\mathrm{eq}}$ : equilibrium adsorption constant (torr ${ }^{-1}$ ) and $\mathrm{P}_{\mathrm{HNO}_{3}}$ : $\mathrm{HNO}_{3}$ vapour pressure ( 1 torr $=1.333222 \mathrm{hPa}$ ). $\theta$ is usually defined as the ratio of the total number of adsorbed molecules on a surface to 20 the total number of sites available for adsorption on the surface. The number of sites has a typical value of $\approx 10^{15} \mathrm{~cm}^{-2}$.

Hynes et al. (2002) derive from their measurements at $218 \mathrm{~K}$ as well as from those of Abbatt (1997) at $228 \mathrm{~K}$ the equilibrium adsorption constants $\mathrm{K}_{\mathrm{eq}}$. The dissociative Langmuir isotherms for $\mathrm{HNO}_{3}$ uptake on ice are plotted in Fig. 4, upper left panel.

\section{ACPD}

3, 413-443, 2003

Nitric acid in cirrus clouds

M. Krämer et al.

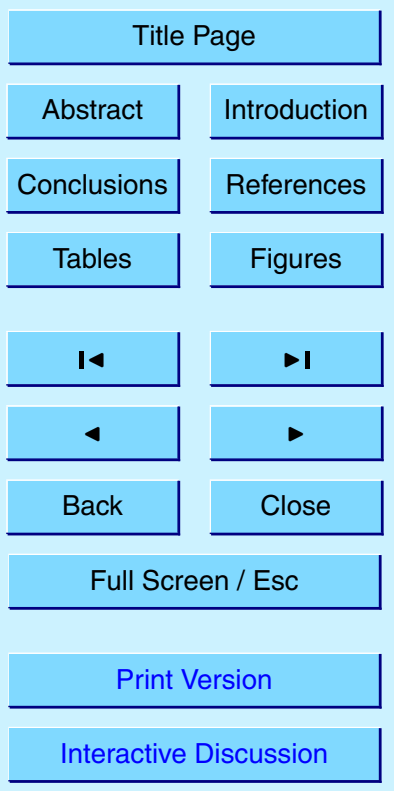

(C) EGU 2003 
Laboratory study of Hudson et al. (2002) (209K - 220K): In an also very recent laboratory study on uptake of $\mathrm{HNO}_{3}$ on thin ice films (black plus in Fig. 4, only the data points marked as saturated coverages by Hudson et al. (2002) are plotted here) one series of measurements ranges from $210-220 \mathrm{~K}$ at a $P_{\mathrm{HNO}_{3}}$ of $1.1 \cdot 10^{-6} \mathrm{hPa}$ and 5 another series from $216-217 \mathrm{~K}$ at $2 \cdot 3 \cdot 10^{-6} \mathrm{hPa}$.

Hudson et al. (2002) found lower $\mathrm{HNO}_{3}$ coverages for the same $P_{\mathrm{HNO}_{3}}$ as Abbatt (1997) and Hynes et al. (2002) and state a much stronger temperature dependence of the $\mathrm{HNO}_{3}$ uptake on ice films. They applied a multilayer Frenkel-Halsey-Hill (FFH) model to their data in order to describe the temperature dependence of the $\mathrm{HNO}_{3}$ uptake at constant $P_{\mathrm{HNO}_{3}}$.

Model study of Tabazadeh et al. (1999) (210K - 240K): The surface chemistry model developed by Tabazadeh et al. (1999) describes Langmuir like dissociative uptake of $\mathrm{HNO}_{3}$ and $\mathrm{HCl}$ on ice for upper tropospheric $P_{\mathrm{HNO}_{3}}\left(=2.67 \cdot 10^{-8} \mathrm{hPa}\right)$. 15 They found increasing $\mathrm{HNO}_{3}$ uptake with decreasing temperature and increasing ice number density ( $\propto$ ice surface area, see also Fig. 3 ). Sensitivity studies for this model performed by Meier and Hendricks (2002), show that the degree of $\mathrm{HNO}_{3}$ uptake on ice is strongly controlled by the adsorption free energy $\Delta G_{\text {ads }}$. Tabazadeh et al. (1999) adjusted $\Delta G_{\text {ads }}$ to the laboratory measurements of Abbatt (1997) and Zondlo et al. 20 (1997) at about 230K and assumed it to be independent from the temperature.

For a comparison of model calculations and measurements, we calculate $\mathrm{HNO}_{3}^{\text {cov }}$ using this model for the conditions prevailing in the field studies POLSTAR and SUCCESS and the laboratory study of Arora et al. (1999) (open rectangles with the colours of the respective experiments in Fig. 4, upper right panel; note that no model 25 calculations were performed for the studies of Abbatt (1997) and Zondlo et al. (1997) because the model is adjusted to those measurements).

\section{ACPD}

$3,413-443,2003$

\section{Nitric acid in cirrus} clouds

M. Krämer et al.

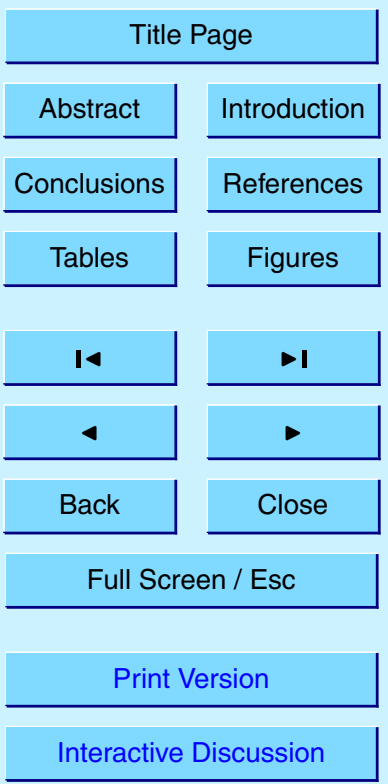

(C) EGU 2003 
At first we would like to note here that we assume that in the field experiments the ice particles are already equilibrated with the gaseous $\mathrm{HNO}_{3}$. This assumption is based 5 on box model calculations on uptake of water and $\mathrm{HNO}_{3}$ by interstitial and ice particles for the conditions of POLSTAR 1997 performed by Meilinger et al. (1999). Meilinger et al. (1999) show that at the point of observation the ice particles were exposed to gaseous $\mathrm{HNO}_{3}$ for 25 hours which should have been long enough to equilibrate with the gas phase. Nevertheless, a substantial amount of the $\mathrm{HNO}_{3}$ was found in the gas phase in similarity to the other field experiments shown here (see Table 3).

All data from the field and laboratory measurements are plotted versus $P_{\mathrm{HNO}_{3}}$ together with the Langmuir isotherms derived by Hynes et al. (2002) in the upper left panel of Fig. 4. Note that the isotherms are sorted descending with ascending temperature. It can be seen that the low coverages detected in the field $(0.001-0.04$ monolayer) seems to follow the isotherms down to the small $P_{\mathrm{HNO}_{3}}$ typical for the upper troposphere. The coverages measured by Arora et al. (1999) on ice particles for higher $P_{\mathrm{HNO}_{3}}$ (around 0.1 monolayer) are in fact higher, but on the other hand they seem to be low compared to the plotted isotherms when taking into account that the difference between the two isotherms is $10 \mathrm{~K}$ and the difference between the lower isotherm and the data of Arora et al. (1999) is only $5 \mathrm{~K}$. To get a better impression how the field data matches the isotherms, the figure is plotted with a logarithmic $P_{\mathrm{HNO}_{3}}$ axis (Fig. 4, lower left panel). Here, it becomes obvious, that the coverages measured for ice particles, residing in the range of $0.001-0.1$ monolayer and decreasing with $P_{\mathrm{HNO}_{3}}$ and temperature, are low compared to the isotherms derived from the laboratory measurements upper $218 \mathrm{~K}$ isotherm and should therefore be placed above it, if the $\mathrm{HNO}_{3}$ uptake on ice particles would be Langmuir like and descending with ascending temperature as described by Hynes et al. (2002) for ice films.

\section{Nitric acid in cirrus clouds}

M. Krämer et al.

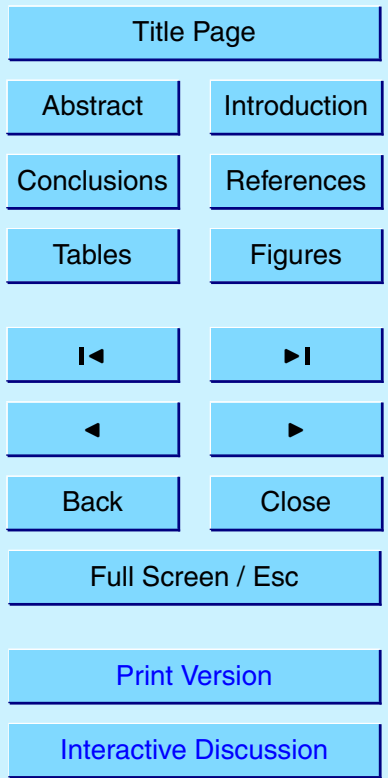

(C) EGU 2003 
In this case, an increase of $\mathrm{HNO}_{3}$ coverage with decreasing temperature should be observed for a certain $P_{\mathrm{HNO}_{3}}$, as is found in the laboratory studies on ice films by Abbatt (1997) and Hynes et al. (2002) and also, but much stronger, by Hudson et al. (2002)

(see Fig. 4, upper right panel). Altogether the coverage on ice films increases from

$50.1-0.8$ monolayer while the temperature is decreasing from $250 \mathrm{~K}$ to $210 \mathrm{~K}$. However, the observations for ice particles show a strong decrease of $\mathrm{HNO}_{3}$ coverage with temperature in the range of $230 \mathrm{~K}$ to $196 \mathrm{~K}$. Even when raising the coverages from the field experiments Langmuir like to the higher $P_{\mathrm{HNO}_{3}}$ of the laboratory measurements, they will be decreasing with temperature and lower than expected from the laboratory 10 measurements.

However, the field data also does not match the FFH theory described by Hudson et al. (2002) with the exception of the data point of Weinheimer et al. (1998). Meilinger et al. (1999) supposed a thin ternary liquid layer coating the ice particles to explain the difference between the low POLSTAR 1997 coverages and those measured by Abbatt 15 (1997). But in this case one would expect decreasing $\mathrm{HNO}_{3}$ uptake at higher temperatures, which is in contrast to the observations. Possibly the observed $\mathrm{HNO}_{3}$ uptake on ice particles can be described by dissociative Langmuir isotherms where the coverage decreases for descending temperatures. With this concept of $\mathrm{HNO}_{3}$ uptake on ice particles the observed dependence on $P_{\mathrm{HNO}_{3}}$ and temperature could be explained. 20 However, more field and laboratory measurements on ice particles are highly recommended to consolidate this hypothesis.

4.2.2. Model results in comparison with the measurements

The results of the $\mathrm{HNO}_{3}$ coverages calculated for the conditions prevailing in the field/laboratory studies with the surface chemistry model adapted from Tabazadeh et al. 25 (1999) are presented in Fig. 4 (upper right panel) as open rectangles with the colours of the respective experiments.

The measurements of Arora et al. (1999), made in the same temperature range as those of Abbatt (1997), are well represented by the Langmuir model. But the

\section{Nitric acid in cirrus clouds}

M. Krämer et al.

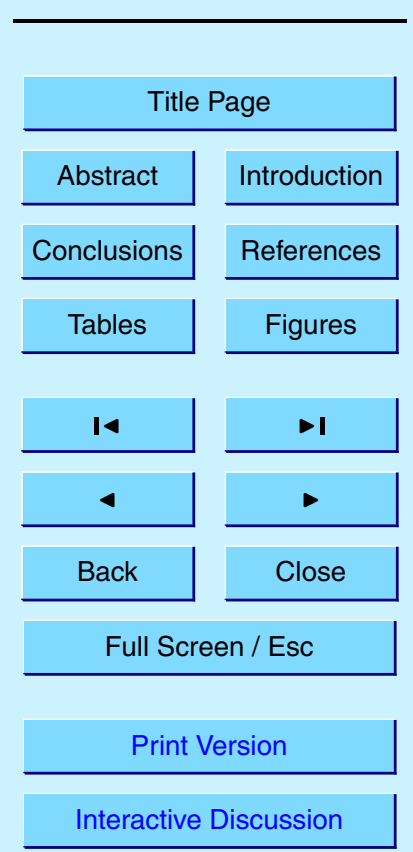

(C) EGU 2003 
model $\mathrm{HNO}_{3}^{\text {cov }}$ determined for the colder POLSTAR and SUCCESS conditions deviate strongly from the measurements. The discrepancy between modeled and measured $\mathrm{HNO}_{3}^{\mathrm{cov}}$ is larger than the uncertainty of the measurements. Probably the adjustment of the Langmuir model to the measured coverages of Abbatt (1997) does not hold for 5 lower temperatures, which leads to an overestimation the modeled uptake of $\mathrm{HNO}_{3}$ on ice in this temperature range.

\subsubsection{Adsorption free energies and enthalpies}

Adsorption free energy $\Delta G_{\text {ads }}$ (from model): In the model of Tabazadeh et al. (1999) 10 the parameter controlling the uptake of $\mathrm{HNO}_{3}$ on ice is the adsorption free energy $\Delta G_{\text {ads }}$ (see Sect. 4.1), which was assumed to be independent from the temperature. This assumption holds for the measurements of Abbatt (1997) on ice films (also shown by Tabazadeh et al. (1999)) and for those of Arora et al. (1999) on ice particles (see Sect. 4.2.2). But, based on the new field measurements at cold temperatures we

15 suspect that the amount of the adsorption free energy could be lower for ice particles at lower temperatures. A possible explanation may be that the strength of the hydrogen bonds and/or the ice surface structure depends on the temperature.

Using the Langmuir surface chemistry model, we derive a temperature dependent $\Delta G_{\text {ads }}$ adjusted to the measured $\mathrm{HNO}_{3}^{\text {cov }}$. For this purpose, we varied $\Delta G_{\text {ads }}$ in the 20 model until the modeled $\mathrm{HNO}_{3}^{\mathrm{cov}}$ matches the measured values. The values found for $\Delta G_{\text {ads }}$ (for those experiments containing all information necessary for the model calculations) are plotted in Fig. 4 (lower right panel, symbols and colours of the respective experiments; $\Delta G_{\text {ads }}$ for Abbatt (1997) is taken from Tabazadeh et al. (1999)). The magenta dotted line is the empirically derived exponential function fitting the adjusted $\Delta G_{\text {ads }}$ :

$\Delta G_{\text {ads }}=-14.31+5.93 \cdot 10^{15} * e^{-0.154 \cdot T}\left(\mathrm{kcal} \cdot \mathrm{mol}^{-1}\right)$

ACPD

3, 413-443, 2003

Nitric acid in cirrus clouds

M. Krämer et al.

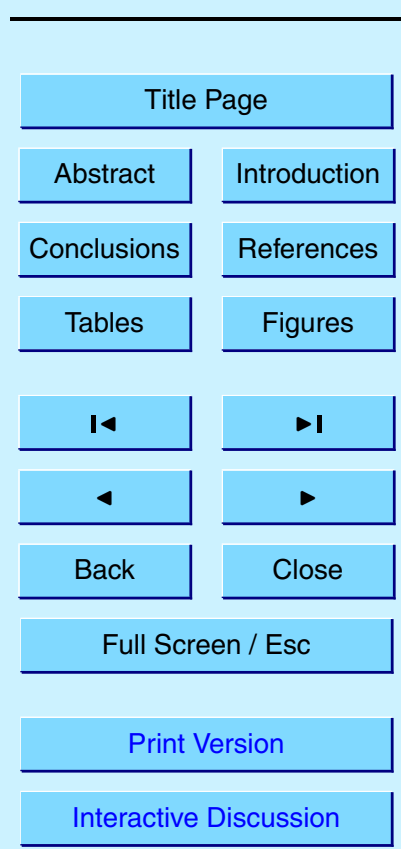

(C) EGU 2003

with $T$ : temperature $(K)$. We suggest to use this empirical function for $\Delta G_{\text {ads }}$ in 431 
Langmuir dissociative uptake models to characterise more precisely the $\mathrm{HNO}_{3}$ uptake ACPD on ice even if the questions on the physical process of $\mathrm{HNO}_{3}$ uptake is not yet completely understood.

$3,413-443,2003$

$5 \quad$ Adsorption free enthalpy $\Delta H_{\text {ads }}$ (from measurements): As $\Delta G=\Delta H-T \Delta S(H$ : free enthalpy, $S$ : entropy), the adsorption free enthalpy $\Delta H_{\text {ads }}$ should follow a function similar to that for $\Delta G_{\text {ads }}$ but shifted by $T \Delta S$.

Adamson (1990) provides a formula for $K_{\text {eq }}$ in dependence on $\Delta H_{\text {ads }}$. Solving this formula with regard to $\Delta H_{\text {ads }}$ yields:$$
\Delta H_{\mathrm{ads}}=-R T \cdot \ln \left(\mathrm{K}_{\mathrm{eq}} \cdot \frac{v_{0} \cdot \sqrt{2 \pi \cdot \mathrm{m}_{\mathrm{HNO}_{3} \cdot \mathrm{k}_{\mathrm{B}} \cdot \mathrm{T}}}}{133.33 \cdot \alpha \cdot \sigma_{0}}\right)\left(\mathrm{J} \cdot \mathrm{mol}^{-1}\right)
$$

with $H_{\text {ads }}$ : adsorption free enthalpy $\left.\left(\mathrm{J} \cdot \mathrm{mol}^{-1}\right) ; 1 \mathrm{cal}=4.187 \mathrm{~J}\right) . R=N_{\mathrm{A}} \cdot \mathrm{k}_{\mathrm{B}}=8.314$ $J \cdot(K \cdot \mathrm{mol})^{-1}, T$ : temperature $(K), N_{\mathrm{A}}$ : Avogadro's constant $=6.0221 \cdot 10^{23} \mathrm{~mol}^{-1}, k_{\mathrm{B}}$ : Boltzmann's constant $=1.381 \cdot 10^{-23} \mathrm{~J} \cdot \mathrm{K}^{-1}, v_{0}$ : frequency of surface atomic vibrations $=10^{13} \mathrm{sec}^{-1}, \mathrm{~m}_{\mathrm{HNO}_{3}}:$ weight of one adsorbed molecule $=M_{\mathrm{HNO}_{3}} / N_{\mathrm{A}}(\mathrm{kg}), M_{\mathrm{HNO}_{3}}=63.0$ $15 \cdot 10^{-3} \mathrm{~kg} \cdot \mathrm{mol}^{-1}, \alpha$ : accommodation coefficient of the adsorbed gas on the surface = 0.9 and $\sigma_{0}$ : molecular area of one site $=10^{-19} \mathrm{~m}^{2}$.

Using additionally Eq. (1) solved for $K_{\text {eq }}$, we determined the values for $\Delta H_{\text {ads }}$ for those measured data containing all necessary information. The results are plotted in Fig. 4 (lower right panel, symbols and colours of the respective experiments; $\Delta G_{\text {ads }}$ for 20 Abbatt (1997) and Hynes et al. (2002) is taken from Hynes et al. (2002)). The grey dotted line is the empirical fitted function fitting the adjusted $\Delta H_{\text {ads }}$.

It becomes obvious that the shape of the function for $\Delta H_{\text {ads }}$ indeed follows that of $\Delta G_{\text {ads }}$ with the expected shift $T \Delta S$. This finding supports the hypothesis of a temperature dependent adsorption process for $\mathrm{HNO}_{3}$ on ice.

\section{Nitric acid in cirrus clouds}

M. Krämer et al.

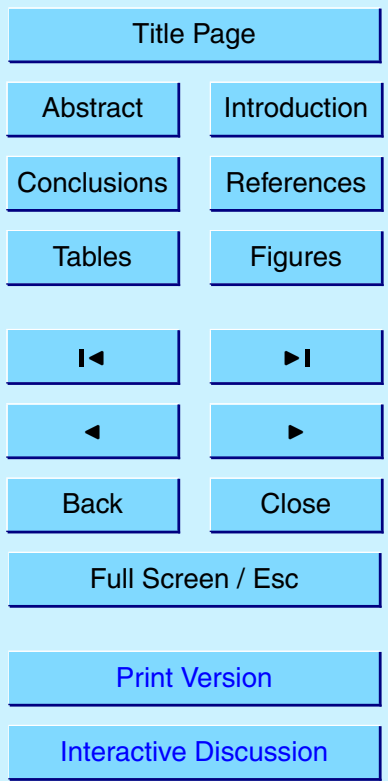

(C) EGU 2003 


\section{Conclusions}

From a synopsis of the cirrus field experiments SUCCESS 1996 (Weinheimer et al., 1998), POLSTAR 1997 (Meilinger et al., 1999) and POLSTAR 1998, the laboratory studies of Arora et al. (1999), Abbatt (1997), Hynes et al. (2002) and Hudson et al. 5 (2002) as well as the model studies of Tabazadeh et al. (1999) and Meier and Hendricks (2002) we developed a first overview of the partitioning of nitric acid in cirrus clouds including a new hypothesis on the $\mathrm{HNO}_{3}$ uptake on ice.

Concerning the partitioning in cirrus clouds we found that a substantial part of nitric acid can remain in the gas phase. The distribution of the removed nitric acid between interstitial aerosol and ice particles is dependent on temperature and ice surface area, respectively. In cold cirrus clouds $(<205 \mathrm{~K})$ with small ice surface areas the partitioning is strongly in favour of the interstitial particles while in warmer cirrus clouds with large ice surface areas the uptake on ice preponderates. Consequently, extensive uptake of nitric acid on ice with subsequent denitrification likely occurs only in warm cirrus clouds which are more abundant in the upper troposphere.

From the present field and laboratory measurements on ice particles and ice films it is not possible to derive a general picture on the mechanisms of $\mathrm{HNO}_{3}$ uptake. However, the observed $\mathrm{HNO}_{3}$ uptake on ice particles $(0.001-0.1$ monolayer, decreasing with temperature and $\left.P_{\mathrm{HNO}_{3}}\right)$ is lower than the uptake on ice films $(0.1-0.8$ monolayer, increasing with decreasing temperature) and maybe described by dissociative Langmuir isotherms where the coverage decreases for descending temperatures. Such a concept of the $\mathrm{HNO}_{3}$ uptake on ice particles could explain the observed dependence on temperature and $P_{\mathrm{HNO}_{3}}$. But, to consolidate this hypothesis, more field and laboratory measurements on ice particles are needed.

25 The $\mathrm{HNO}_{3}$ measurements are compared with the global offline tracer model of Lawrence and Crutzen (1998) and the Langmuir surface chemistry model of Tabazadeh et al. (1999): Lawrence and Crutzen (1998) estimated the denitrification of the upper troposphere using a parameterization for the partitioning of nitric acid in dependence
ACPD

$3,413-443,2003$

Nitric acid in cirrus clouds

M. Krämer et al.

Title Page

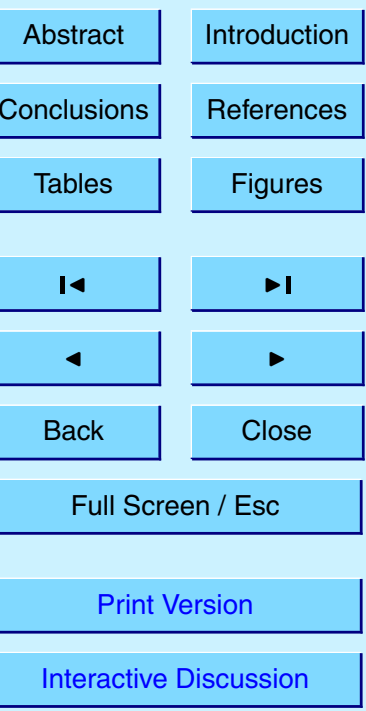

(C) EGU 2003 
on the ice surface area of the cirrus clouds. Compared to the measurements the parameterised values are higher to about a factor of $2-10$, which probably leads to an overestimation of the denitrification of the upper troposphere by sedimenting cirrus cloud particles. The partitioning calculated by Tabazadeh et al. (1999) using a dissocia5 tive Langmuir surface chemistry model also exceed the measured values, escpecially for colder temperatures. $\mathrm{HNO}_{3}$ coverages of ice particles determined with that model agree with the measurements in the temperature range where the model is adjusted to $(220-230 \mathrm{~K})$. For temperatures $\leq 210 \mathrm{~K}$ the model shows much higher uptake than the measurements, which can be attributed to a constant adsorption free energy assumed 10 for the model calculations.

Finally, the adsorption free energies and enthalpies for $\mathrm{HNO}_{3}$ uptake on ice are estimated from the coverage measurements. Both variables are found to depend on temperature. An empirically function $\Delta G_{\text {ads }}(T)$ is derived and recommended here for use in surface chemistry models.

15 Acknowledgements. Part of this work is funded by Bundesministerium für Bildung und Forschung $(\mathrm{BMB}+\mathrm{F})$. H. Ziereis contributed considerably to the success of this work through many helpful discussions. Like always, many thanks to P. for language advise. This work is dedicated to my father J. Krämer.

\section{References}

Abbatt, J.: Interaction of $\mathrm{HNO}_{3}$ with water-ice surfaces at temperatures of the free troposphere, Geophys. Res. Lett., 24, 1479-1482, 1997. 416, 426, 427, 428, 430, 431, 432, 433, 443

Adamson, A. W.: Physical chemistry of surfaces, $5^{\text {th }}$ Ed., John Wiley, New York, 591-705, 1990. 432

Arora, O., Cziczo, D., Morgan, A., Abbatt, J., and Niedziela, R.: Uptake of nitric acid by submicron-sized ice particles, Geophys. Res. Lett., 26, 3621-3621, 1999. 416, 423, 425, 426, 428, 429, 430, 431, 433

Carslaw, K. S., Luo, B., and Peter, T.: An analytic expression for the composition of aqueous

\section{ACPD}

$3,413-443,2003$

\section{Nitric acid in cirrus clouds}

M. Krämer et al.

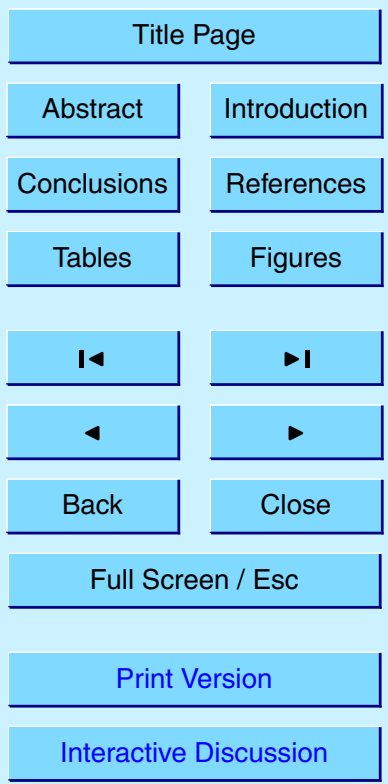

(C) EGU 2003 
$\mathrm{HNO}_{3}-\mathrm{H}_{2} \mathrm{SO}_{4}$ stratospheric aerosols including gas phase removal of $\mathrm{HNO}_{3}$, Geophys. Res. Lett., 14, 1877-1880, 1995, (http://www.hpc1.uea.ac.uk/ e770/aim.html). 420, 424, 439

Clegg, S. L., Brimblecombe, P., and Wexler, A. S.: A thermodynamic model of the system $\mathrm{HCl}-$ $\mathrm{NH}_{4}-\mathrm{SO}_{4}-\mathrm{NO}_{3}-\mathrm{H}_{2} \mathrm{O}$ at tropospheric temperatures, J. Phys. Chem., 102A, 2137-2154, 1998. 421,439

5 Diehl, K., Mitra, S., and Pruppacher, $\mathrm{H} .:$ A laboratory study of the uptake of $\mathrm{HNO}_{3}$ and $\mathrm{HCl}$ vapor by snow crystals and ice spheres at temperatures between 0 and $-40^{\circ} \mathrm{C}$, Atmos. Env., 29, 975-981, 1995. 415

Feigl, C., Schlager, H., Ziereis, H., Curtius, J., Arnold, F., and Schiller, C.: Observation of $\mathrm{NO}_{\mathrm{y}}$ uptake by particles in the arctic tropopause region at low temperatures, Geophys. Res.

10 Letters, 26, 2215-2218, 1999. 418, 437

Hudson, P. K., Shilling, J. E., Tolbert, M. A., and Toon, O. B.: Uptake of nitric acid on ice at tropospheric temperatures: Implications for cirrus clouds, J. Phys. Chem. A, 106, 98749882, doi:10.1021/jp020508j, 2002. 416, 417, 426, 428, 430, 433, 439

Hynes, R. G., Fernandez, M. A., and Cox, R. A.: The uptake of $\mathrm{HNO}_{3}$ on water ice and the co-adsorption of $\mathrm{HNO}_{3}$ and $\mathrm{HCl}$ in the temperature range 210-235K, J. Geophys. Res., , 107, 4797, doi:10.1029/2001JD001557, 2002. 416, 426, 427, 428, 429, 430, 432, 433, 443

Kärcher, B. and Solomon, S.: On the composition and optical extinction of particles in the tropopause region, J. Geophys. Res., 104, 27,441-27,459, 1999. 421

Lawrence, M. and Crutzen, P.: The impact of cloud particle gravitational settling on soluble trace gas distributions, Tellus, 50B, 263-289, 1998. 414, 415, 417, 422, 424, 425, 433, 442

Meier, A. and Hendricks, J.: Model studies on the sensitivity of upper troposheric chemistry to heterogeneous uptake of $\mathrm{HNO}_{3}$ on cirrus ice particles, J. Geophys. Res., 107, 4696, doi:10.1029/2001JD000735, 2002. 416, 423, 428, 433, 439, 441

Meilinger, S., Tsias, A., Dreiling, V., et al.: $\mathrm{HNO}_{3}$ partitioning in cirrus clouds, Geophys. Res. 25 Lett., 26, 2207-2210, 1999. 416, 417, 418, 421, 422, 423, 426, 429, 430, 433, 438, 439

Petzold, A., Hoell, C., Kärcher, B., Beuermann, J., Schiller, C., Ziereis, H., and Schlager, H.: Observations of aerosol properties above ice saturation in the polar tropopause region, $\mathrm{J}$. Geophys. Res., 105, 29,387-29,395, 2000. 415, 419, 420, 437

Schiller, C., Afchine, A., Eicke, N., et al.: Ice particle formation and sedimentation in the tropopause region: A case study based on in situ measuremenst of total water during polstar 1997, Geophys. Res. Lett., 26, 2219-2222, 1999. 419, 437

Schlager, $\mathrm{H}$. et al.: In situ observations of particulate $\mathrm{NO}_{\mathrm{y}}$ in cirrus clouds for different atmo-

\section{Nitric acid in cirrus clouds}

M. Krämer et al.

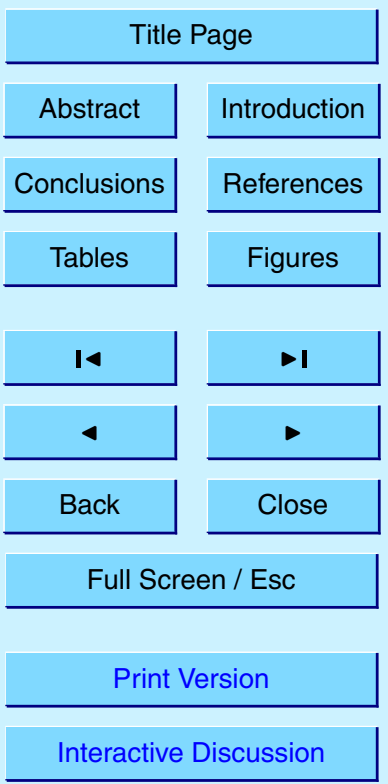

C) EGU 2003 
spheric conditions. Proceedings of the workshop "Aviation, aerosols, contrails and cirrus clouds (A2C3)", 10-12 July 2000, Seeheim (Frankfurt), Germany, 68-73, 2002. 420, 439

ACPD

Schneider, J., Arnold, F., Bürger, V., et al.: Nitric acid $\left(\mathrm{HNO}_{3}\right)$ in the upper troposphere and lower stratosphere at midlatitudes: New results from aircraft-based mass spectrometric measurements, J. Geophys. Res., 103, 25,337-25,343, 1998. 419, 437

5 Tabazadeh, A., Toon, O. P., and Jensen, E. J.: A surface chemistry model for nonreactive trace gas adsorption on ice: Implications for nitric acid scavenging by cirrus, Geophys. Res. Letters, 26, 2211-2214, 1999. 414, 416, 417, 422, 425, 426, 428, 430, 431, 433, 434, 442, 443

Weinheimer, A. J., Campos, T. L., Walega, J. G., Grahek, F. E., Rodley, B. A., Twohy, B. D. C. H., and Gandrud, B.: Uptake of $\mathrm{NO}_{\mathrm{y}}$ on wave-cloud ice particles, Geophys. Res. Lett., 25, 17251728, 1998. 416, 423, 426, 430, 433, 439

Ziereis, H., Schlager, H., Schulte, P., van Velthofen, P., and Slemr, F.: Distribution of $\mathrm{NO}, \mathrm{NO}_{\mathrm{x}}$ and $\mathrm{NO}_{y}$ in the upper troposphere and lower stratosphere between 28 and $61^{\circ} \mathrm{N}$ during POLINAT 2, J. Geophys. Res., 105, 3653-3664, 2000. 418, 437

Zondlo, M., Barone, S., and Tolbert, M.: Uptake of $\mathrm{HNO}_{3}$ on ice under tropospheric conditions, Geophys. Res. Lett., 24, 1391-1394, 1997. 416, 428

3, 413-443, 2003

Nitric acid in cirrus clouds

M. Krämer et al.

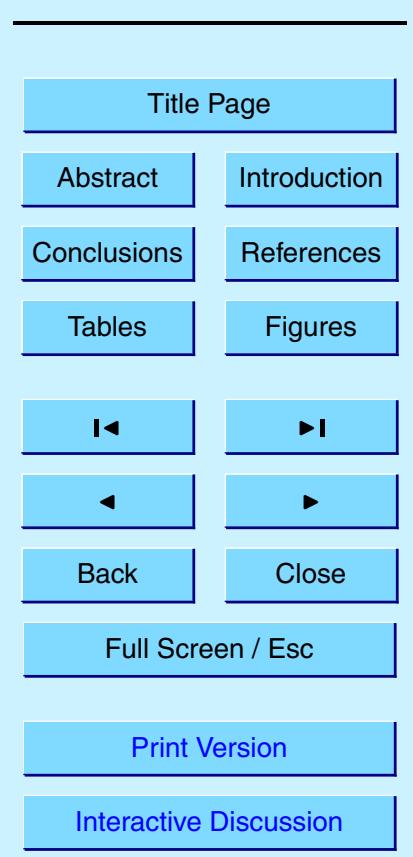

(C) EGU 2003 


\section{ACPD}

$3,413-443,2003$

\section{Nitric acid in cirrus clouds}

M. Krämer et al.

Table 1. Instruments on board of the "Deutsches Zentrum für Luft- und Raumfahrt" (DLR) research aircraft Falcon during POLSTAR 1998 (the instrumental setup used for POLSTAR 1997 is identical with the exception of the particle measurement performed with CPC and MASP (Multi Angle Spectrometer Probe))

\begin{tabular}{|c|c|c|c|}
\hline Instrument & Acronym & Parameter & Reference \\
\hline Ion Molecular Reaction Mass Spectrometer & IMRMS & $\mathrm{HNO}_{3}^{\text {gas }}$ & Schneider (1998) \\
\hline Forward-backward $\mathrm{NO}_{\mathrm{y}}$ detector & - & $\left(\mathrm{NO}_{\mathrm{y}}^{\mathrm{ice}}\right)_{\max }$ & Ziereis et al. (2000) \\
\hline Fast In situ Stratospheric Hygrometer & FISH & $\begin{array}{c}\approx\left(\mathrm{HNO}_{3}^{\mathrm{ice}}\right)_{\max } \\
\mathrm{H}_{2} \mathrm{O}\end{array}$ & $\begin{array}{l}\text { Feigl et al. (1999) } \\
\text { Schiller et al. (1999) }\end{array}$ \\
\hline Ultrafine Condensation Particle Counter & UCPC & particles, $\mathrm{r}_{p}>2.5 \mathrm{~mm}$ & Petzold et al. (2000) \\
\hline Condensation Particle Counter & CPC & particles, $r_{p}>7.0 \mathrm{~mm}$ & Petzold et al. (2000) \\
\hline Forward Scattering Spectrometer Probe & FSSP & particles, $r_{p}=0.3-20 \mu \mathrm{m}$ & Petzold et al. (2000) \\
\hline
\end{tabular}

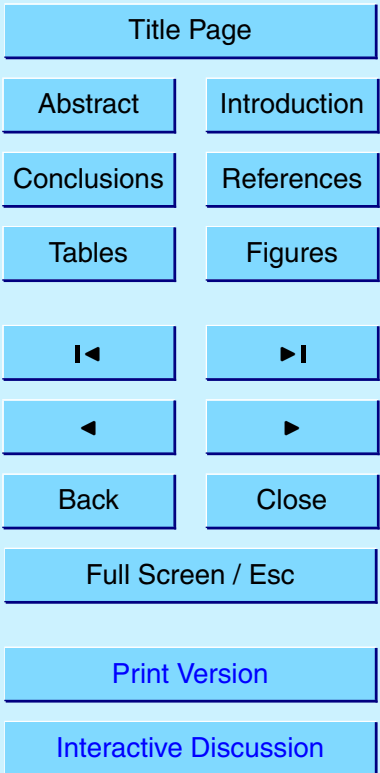

(C) EGU 2003 


\section{ACPD}

$3,413-443,2003$

\section{Nitric acid in cirrus clouds}

M. Krämer et al.

Table 2. Lognormal fit parameters of the average number size distributions for POLSTAR 1997 (derived from CPC and MASP measurements, Meilinger et al., 1999) and for the events I and II of POLSTAR 1998 (derived from UCPC, CPC and FSSP measurements)

\begin{tabular}{lccccccccc}
\hline & \multicolumn{3}{c}{ Polstar 1997 } & \multicolumn{5}{c}{ Polstar 1998 } \\
& & from Meilinger et al. (1999) & \multicolumn{3}{c}{ event I } & \multicolumn{3}{c}{ event II } \\
\hline Mode & & liq. & ice & accum. & haze & ice & accum. & haze & ice \\
$\mathrm{R}_{\text {mod }}$ & $\mu \mathrm{m}$ & 0.05 & 2.6 & 0.05 & 0.475 & 3.0 & 0.05 & 0.35 & 5.0 \\
$\mathrm{~N}$ & $\frac{1}{\mathrm{~cm}^{3}}$ & 156 & 5.3 & 175 & 4.5 & 0.1 & 300 & 4.5 & 1.0 \\
$\sigma$ & 2.25 & 2.01 & 1.7 & 1.4 & 1.75 & 1.7 & 1.4 & 1.75 \\
\hline
\end{tabular}

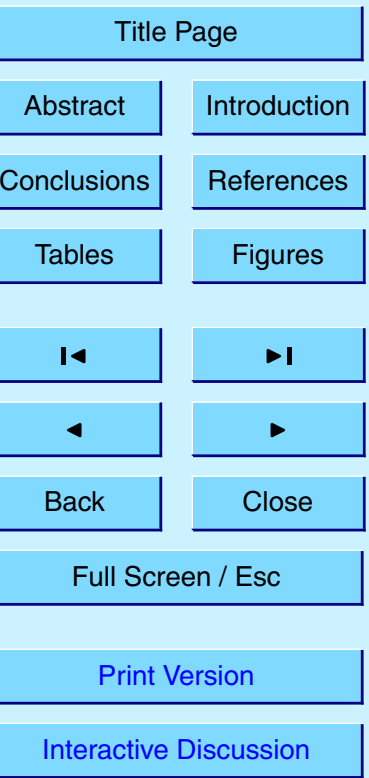

(C) EGU 2003 
Table 3. $\mathrm{HNO}_{3}$ partitioning between gas phase, interstitial aerosol and ice particles in cirrus clouds: a: $\mathrm{HNO}_{3}-\mathrm{H}_{2} \mathrm{SO}_{4}-\mathrm{H}_{2} \mathrm{O}$ interstitial particle composition (ternary solution particles, Carslaw et al. (1995), b: $\mathrm{HNO}_{3}-\mathrm{H}_{2} \mathrm{SO}_{4}-\mathrm{H}_{2} \mathrm{O}+\mathrm{NH}_{3}$, values in [angular brackets] (AIM II: Aerosol Inorganics Model, Clegg et al. (1998), http://www.hpc1.uea.ac.uk/ e770/aim.html); : based on data of Meilinger et al. (1999); §: based on data of Weinheimer et al. (1998) with ॥: data taken from Hudson et al. (2002); ‡: data taken from Meier and Hendricks (2002); †: data taken from Schlager (2002); note that $\mathrm{HNO}_{3}^{\text {cov }} \cdot 10^{-15} \frac{\mathrm{cm}^{2}}{\text { molec }} \equiv$ monolayer $\equiv \theta$; for more details see text

\begin{tabular}{|c|c|c|c|c|c|c|}
\hline & \multicolumn{4}{|c|}{ Field experiments } & \multirow{3}{*}{$\begin{array}{c}\text { Model study } \\
M \& H \\
(2002)^{\ddagger}\end{array}$} & \multirow{3}{*}{$\begin{array}{c}\text { Lab. experiment } \\
\text { Arora et al. } \\
\text { (1999) }\end{array}$} \\
\hline & \multirow[t]{2}{*}{ POLSTAR $1997^{\star}$} & \multicolumn{2}{|c|}{ POLSTAR 1998} & \multirow{2}{*}{$\begin{array}{l}\text { SUCCESS } 1996 \\
\text { Weinh. }(1998)^{\S}\end{array}$} & & \\
\hline & & I & II & & & \\
\hline \multicolumn{7}{|c|}{$\mathrm{HNO}_{3}$ partitioning $(\%)$} \\
\hline Gas phase & 66.5 & 66.2 & $72 \quad[27]$ & 51 & 33 & $65-0.0$ \\
\hline Interst. particles & 33.2 & 33.2 & $21^{\mathbf{a}}[70]^{\mathbf{b}}$ & 0.0 & 0.0 & 0.0 \\
\hline Ice particles & $\begin{array}{c}0.3 \\
(0.1-1.0)\end{array}$ & $\begin{array}{c}0.6 \\
(0.5-1.1)\end{array}$ & $\begin{array}{cc}7 & {[3]} \\
(4.3-15.3)\end{array}$ & $\begin{array}{c}49 \\
(39-65)\end{array}$ & 67 & $35-100$ \\
\hline
\end{tabular}

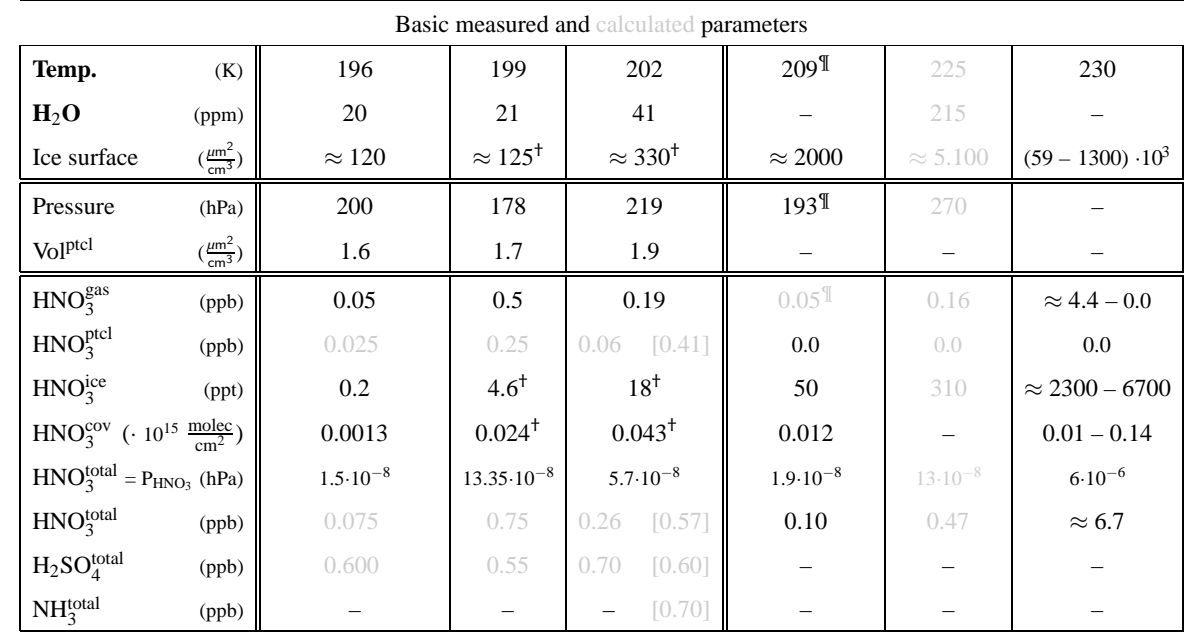

\section{ACPD}

$3,413-443,2003$

Nitric acid in cirrus clouds

M. Krämer et al.

\section{Title Page}

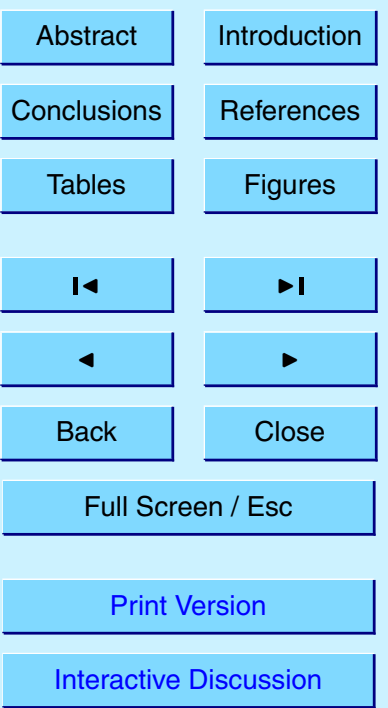

(C) EGU 2003 


\section{ACPD}

POLSTAR - 2, 26. JAN. 1998, M3

$3,413-443,2003$

Event I $\quad$ Event II

\section{Cirrus}
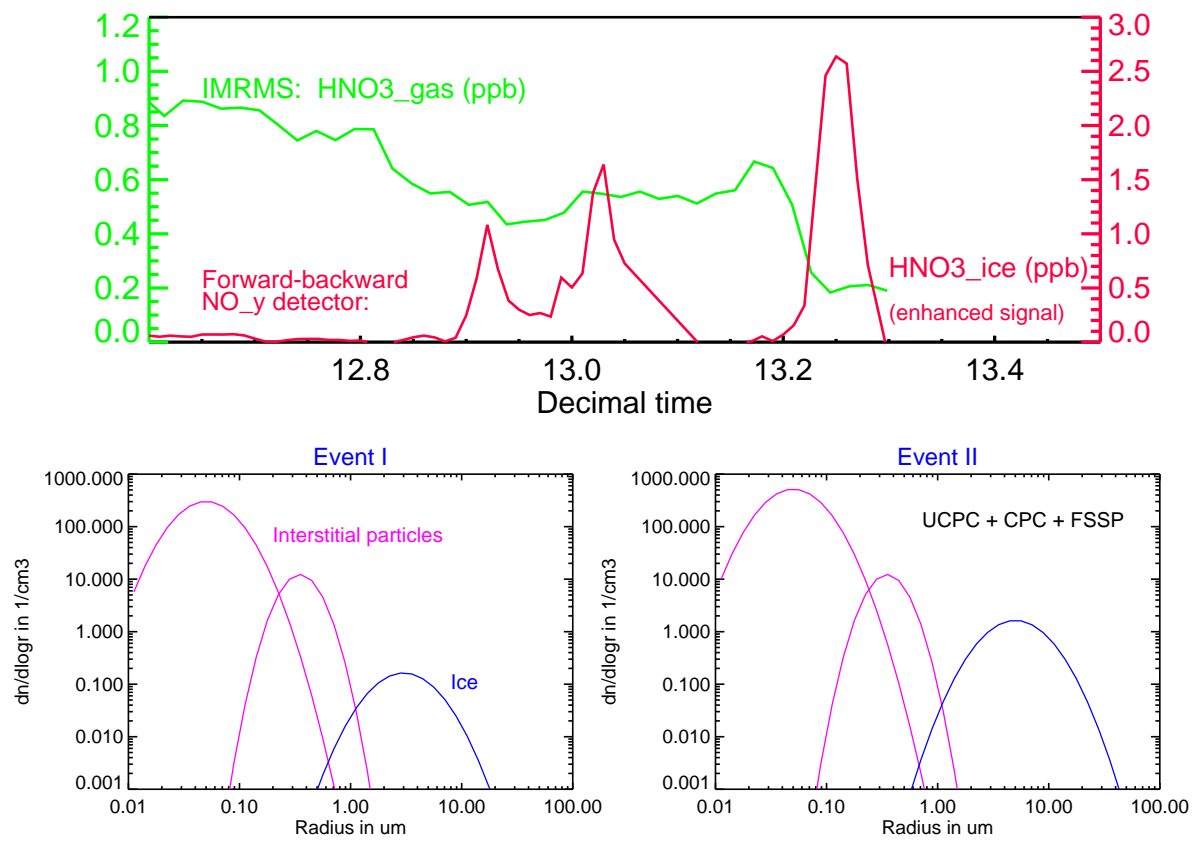

Fig. 1. Measurements of ice particle nitric acid $\left(\mathrm{HNO}_{3}^{\text {ice }}\right)$, nitric acid in the gas phase $\left(\mathrm{HNO}_{3}^{\text {gas }}\right)$ and particle size spectra during the flight M3 from Kiruna to Stockholm on 26 January POLSTAR 1998.

\section{Nitric acid in cirrus clouds}

M. Krämer et al.

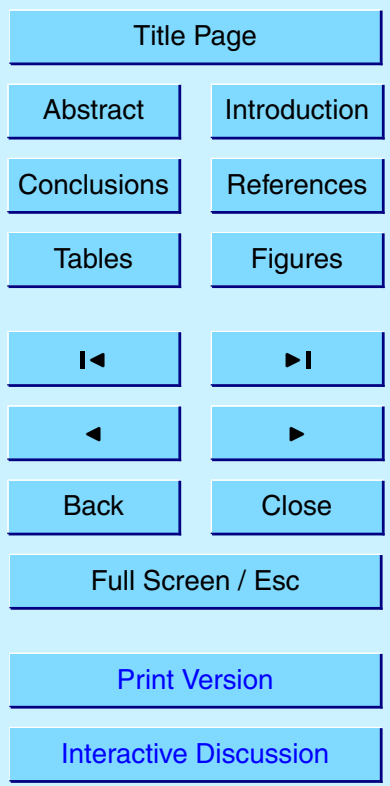

(C) EGU 2003 


\section{ACPD}

$3,413-443,2003$

\section{Nitric acid in cirrus clouds}

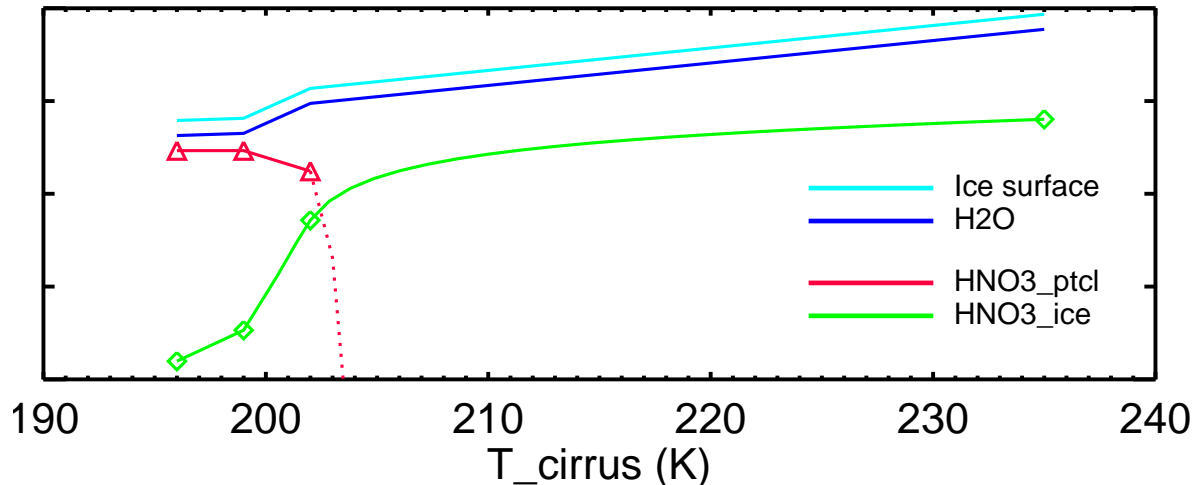

Fig. 2. Schematic diagram (arbitrary units) of the partitioning of nitric acid between interstitial (ternary solution) aerosol and ice particles in cirrus clouds in dependence on cirrus temperature; in addition, the respective $\mathrm{H}_{2} \mathrm{O}$ and ice surface area is shown; the scheme is derived from the POLSTAR experiments and the model study of Meier and Hendricks (2002) (see Table 3). The dotted red line indicates the course of $\mathrm{HNO}_{3}^{\text {ptcl }}$ where measurements are not available.
M. Krämer et al.

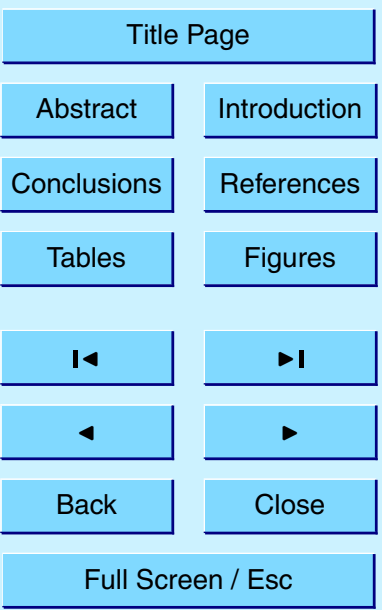

Print Version

Interactive Discussion

(C) EGU 2003 
ACPD

\section{Nitric acid partitioning in cirrus}

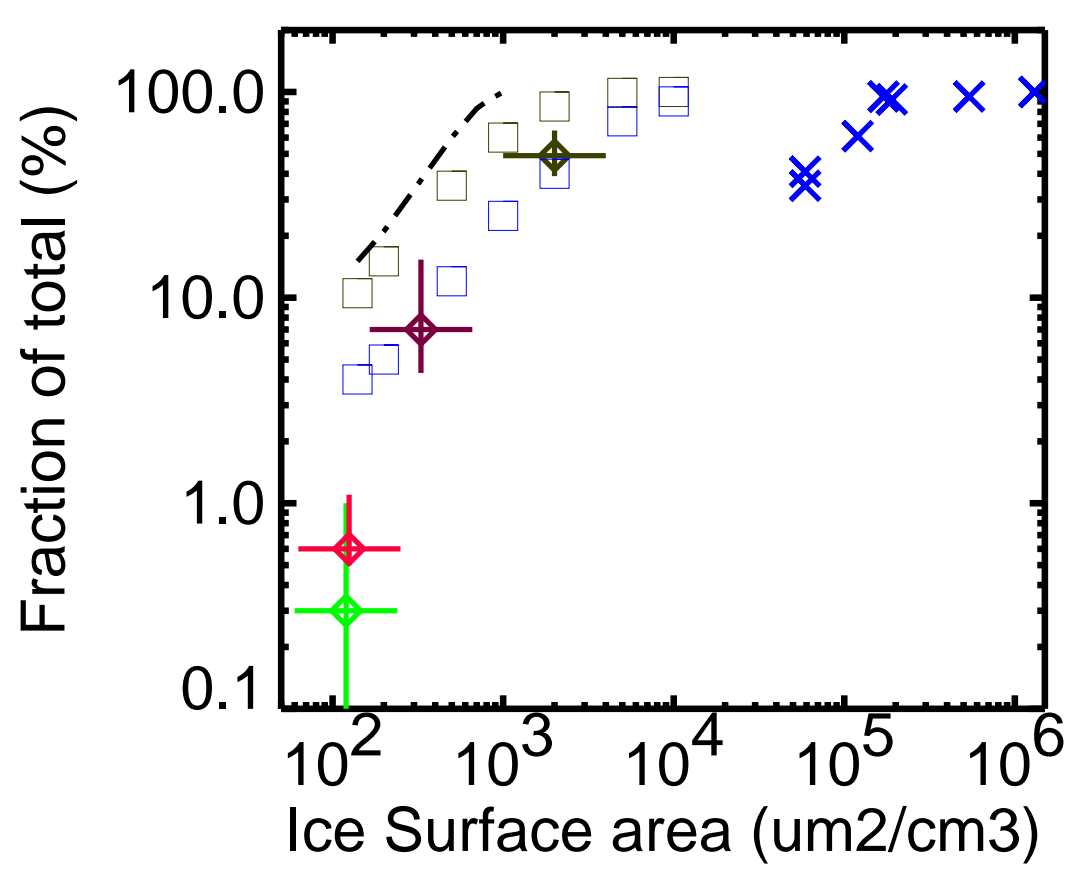

Fig. 3. $\mathrm{HNO}_{3}$ partitioning in cirrus (in \%) versus ice surface area; field and laboratory measurements (legend see Fig. 4) in comparison to the parameterization for low uptake of Lawrence and Crutzen (1998) (dashed dotted line) and model calculations of Tabazadeh et al. (1999) (open rectangles; blue: $230 \mathrm{~K}$, olive: $210 \mathrm{~K}$ ).
3, 413-443, 2003

\section{Nitric acid in cirrus clouds}

M. Krämer et al.

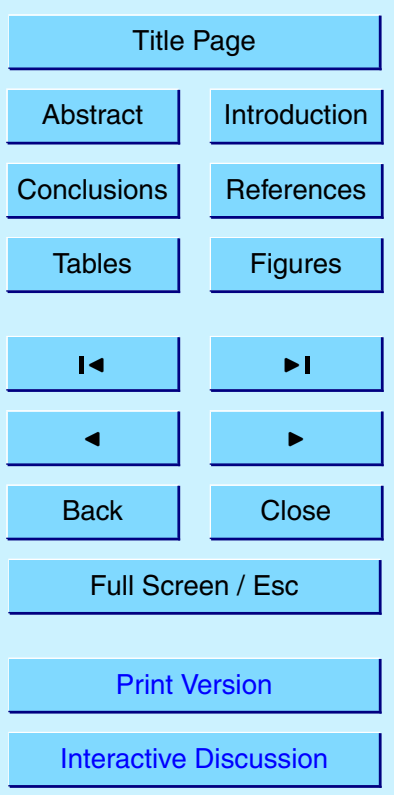

(C) EGU 2003 

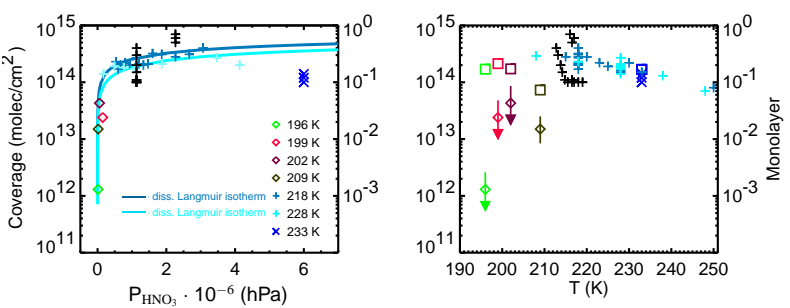

$3,413-443,2003$
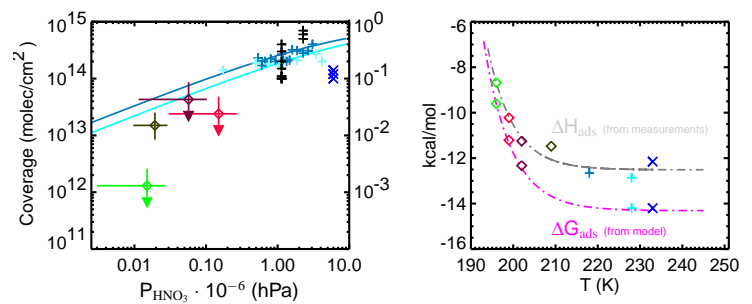

\section{Nitric acid in cirrus clouds}

M. Krämer et al.

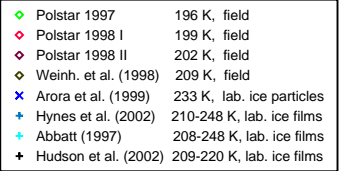

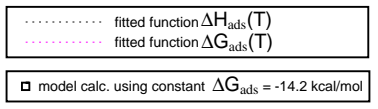

Fig. 4. $\mathrm{HNO}_{3}$ uptake on ice, field and laboratory measurements (coloured symbols, see legend) and model calculations (coloured open squares: the model calculations are performed for the conditions of the measurements using a dissociative Langmuir model with constant adsorption free energy $\Delta G_{\text {ads }}=-14.2 \mathrm{kcal} \cdot \mathrm{mol}^{-1}$, Tabazadeh et al., 1999); the solid lines are dissociative Langmuir-isotherms derived from the measurements. upper left panel: $\mathrm{HNO}_{3}$ coverage versus $P_{\mathrm{HNO}_{3}}$; lower left panel: same as upper left, but logarithmic x-axis; upper right panel: $\mathrm{HNO}_{3}$ coverage versus temperature; lower right panel: $\Delta \mathrm{H}_{\mathrm{ads}}$ and $\Delta \mathrm{G}_{\text {ads }}$ versus temperature; $\Delta \mathrm{H}_{\mathrm{ads}}$ is calculated from the measurements $\left(\Delta \mathrm{H}_{\mathrm{ads}}\right.$ for Abbatt (1997) and Hynes et al. (2002) is taken from Hynes et al. (2002)), $\Delta \mathrm{G}_{\mathrm{ads}}$ is determined using the Langmuir model with variable adsorption free energy ( $\Delta \mathrm{G}_{\mathrm{ads}}$ for Abbatt (1997) is taken from Tabazadeh et al. (1999)); dotted lines: empirical fit functions $\left(\Delta G_{a d s}=-14.31+5.93 \cdot 10^{15} * e^{-0.154 \cdot T}\right)$. For more details see text.

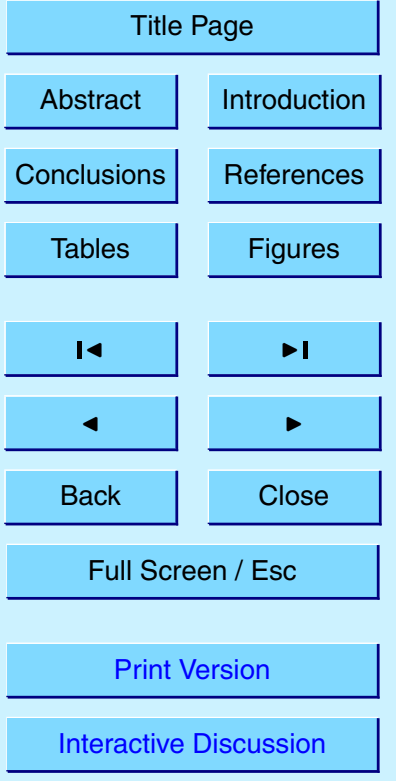

